Portland State University

PDXScholar

$11-1972$

\title{
Die Figur der Rebellen im Frühwerk Schillers: Die Räuber, Kabale und Liebe, Don Carlos
}

\author{
Edward E. Heyen \\ Portland State University
}

Follow this and additional works at: https://pdxscholar.library.pdx.edu/open_access_etds

Part of the German Literature Commons, and the Other German Language and Literature Commons Let us know how access to this document benefits you.

\section{Recommended Citation}

Heyen, Edward E., "Die Figur der Rebellen im Frühwerk Schillers: Die Räuber, Kabale und Liebe, Don Carlos" (1972). Dissertations and Theses. Paper 954.

https://doi.org/10.15760/etd.954

This Thesis is brought to you for free and open access. It has been accepted for inclusion in Dissertations and Theses by an authorized administrator of PDXScholar. Please contact us if we can make this document more accessible: pdxscholar@pdx.edu. 
AN ABSTRACT OF THE THESIS OF Edward E. Heyen for the Master of Arts in German Literature presented November, 1972.

T1tle: D1e Flgur der Rebel1en in Frühwerk Sch111ere: DIe Räuber, Kabale und Ltebe, Don Carlos

APPROVED BY MEMBERS OF THE THESIS COMMITTEE:

H. F. Peters, Chairman

Frank Eaton

Franz Langhammer

Schiller's career as a dramatist spans more than two decades. Without too much difficulty, one observes that his plays are Intimately related with one another. particularly in the storm and stress period, his motives appear to be much the same: Schiller is an advocate of freedom, and the rights of men.

I maintain that the youtheul rebel is a recurrent theme in Schiller's dramatic works and this can be shown by an analysis of four characters from three plays. followed by a sumnary of their similarities.

The rebellious youthe of Schiller are Karl Moor 
(Die Räuber), Ferdinand (Kabale und Llebe), and Don Carlos and Marquis Posa (Don Carlog). These men seek freedom, and hope to have their dreams realized. They want to experience the world, but only on their own terms, as free and unoppressed individuals. It is shown that they are all egolsts, ultimately concerned with the fulfillment of their own needs. At the same time they are moral young men, objecting to the Immorality they encounter. However, their methods of rebellion are naive. This leads to their eventual downfall. Only when it is too late do they realize their inherent falling, when they finally bring the world back into focus.

This thesis explores Schiller's Storm and Stress rebel, a dramatic figure which seems to lack the ruthlessness of a truly rebellious character: Schiller's "rebels" challenge authority on all soclal levels, yet they finally submit to this authority. This is not at all characteristic of the actions of a rebel. It is significant that schiller alters the direction and force of these young heroes. As. Karl Moor turns himself over to the law, the question of motive arises: why does a rebel give himself up? My thesis will outline the reasons for this inconsistency. At the heart of the problem is of course the author. Schiller has decided to reconstruct the "rebel." Why he initiates this alteration 18 an essential part of the study. 
DIE FIGUR DER REBELLEN IM FRÜHWERK SCHILLERS: DIE RÄUBER, KABALE UND LIEBE, DON CARLOS

\author{
by \\ EDWARD B. HEYEN
}

A thesis submitted in partial fulfillment of the requixements for the degree of

MASTER OF ARTS

in

GBRWAN

PORTLAND STATE UNIVERSITY

1972 
TO THE OFFICE OF GRADUATE STUDIES

The members of the Committee approve the thesis of Edward E. Heyen presented in November, 1972.

$$
\text { H. 7. Peters, Chatrman }
$$

Frank Eaton

Franz Langhammer

\section{APPROVED}

R. Carol fealy, Chairman, Departmeht of Forelgn

David T. Clark, Dean of Graduate Studies

November, 1972. 


\section{INHALTSVERZEICHNIS}

KAP ITEL

SEITE

I EINFÜHRUNG $\ldots \ldots \ldots \ldots \ldots \ldots \ldots \ldots \ldots \ldots \ldots$

1

II DIE RÄUBER (KARI MOOR) .............. 3

III KABALE UND LIEBE (FERDINAND) .......... 20

IV DON CARLOS (DON CARLOS/MARQUIS POSA) ... 37

v ZUSAMMENFASSUTG .................... 61

FUSSNOTEN ................................ 68

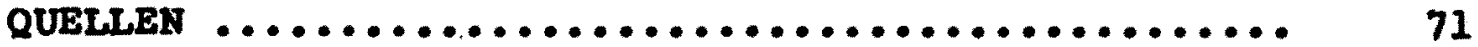




\section{ERSTES KAPITEL.}

\section{E INFÜHRUNG}

Die dramatischen Werke Schillers aind eng miteinander verbunden: ihre Motive beziehen sich auf Fretheit und auf Menschenrechte. Ich behaupte, daB der Junge Rebell ein sich wiederholendes Thema der Dramen dieses Dichters 1st. Beweis dafür liegt in der Analyse von vier Gestalten aus arei Dramen. Daraufhin folgt elne Zusammenfassung, die die Ähnlichkeiten dieser Figuren zeigen wird. Die rebellierenden Jungen Männer Schillers sind Karl Moor (Die Räuber), Ferdinand (Kabale und Llebe), und Don Carlos und Marquis Posa (Don Carlos). Diese Gestalten suchen Preiheit: sie möchten thre Traumbilder verwirklichen. Sie akzeptieren die Beschränkungen der Welt, aber nur auf ihre elgene Weise, als freie, selbständige Menschen. Es stellt sich heraus, daB sie Egoisten sind: sie kümmern sich zu viel un die Erfüllung ihrer elgenen ziele. Zu gleicher Zeit sind ale moralische Menschen, die gegen das Unmoralische in der Welt kämpfen. Das Verhalten dieser Rebellen ist naiv. Deswegen gehen sle letzten Endes zugrunde. Am Rande des Untergangs sehen sie Ihre Fehler ein, Indem die die Welt von einer anderen Perspektive anschauen. Dann lot aber eine hellende Umkehr nicht mehr 
möglich.

Meine These untersucht den Rebellen in einigen Sturm und Drang Dramen Schillers. Diese dramatischen Figuren verfügen aber nicht über die Natur eines wahrhaftigen Rebellen; sle bekämpfen zwar die Gesellschaftsordnung, schlieblich unterwerfen sie sich fedoch dieser Autorität. Solch ein Verhalten entspricht nicht dem Temperament eines Revolutionärs. Bedeutend lst es, daB Schiller die Gesinnung seiner jungen Helden ändert. Als sich Karl Moor der Justiz stellt, taucht die Frage des Motivs auf: warum glbt dieser "Rebell" plötzlich auf? Schiller unternimmt die endgültige Änderung seiner erfolglosen "Rebellen." Der Grund, warum er seine Gestalten aufgeben läBt, let ein wesentlicher Teil der These. 


\section{ZWEITES KAPITEL}

KARI MOOR

Karl Moor, der Verbrecher aus Gewissen, der scheiternde Idealist der Freihelt, der ,heulende Abbadona,' steht der unzerreiBbaren Kette des Schicksaís gegenüber, immer tiefer wird er in das tragische Verhângnis seines Sturzes hineingerissen.1

EIner der bedeutendsten dramatischen Versuche Schillers ist zwischen 1777 und 1780 geschrleben worden. Um diese Zeit befand sich der dichtende Medizinstudent auf elner Militärakademie in stuttgart. Auf der von dem Herzog Karl Eugen gegründeten Schule erfolgte die Erzlehung aff den Fundamenten einer absolutistischen und militärischen Gemeinschaftsbildung. Alle Zöglinge waren standesgemäB, nach Adligen und Bürgerlichen, streng geschieden. Sle führten auch ein genau geregeltes Leben, das nach einem unabänderlichen system von Vorschriften festgelegt war. 2

Für Schiller war diese physische und gelstige Gefangenschaft ein schreckliches Erlebnis. Jahre nachdem er die Anstalt verlassen hatte, dachte er mit Schaudern daran zurück. Eine Auswlrkung davon ist die Flgur des Karl Moor. Die Militärakademie hat eine Phantasieflgur hervorgebracht, an der sich Schillers Einbilaungskraft entzündet hat. Durch elnen Revolutionär redet uns 
ganz unmittelbar die Größe der Schillerachen seole an.

Karl ist ein tatkräftiger Mensch, der die Tatenge seiner zeit erfährt. ${ }^{3}$ Er versucht, der chaotischen Welt zu entfliehen; solche Hoffnungen sind aber unerfüllbar. In der Vorrede $z u$ den Räubern spricht schiller über diesen Rebellen:

Ein Geist, den das äußerste Laster nur reizet um der Gröé willen, die ihm anhänget, um der Kraft willen, die es erheischet, um der Gefahren willen, die es begleiten. Ein merkwürdiger Mensch, ausgestattet mit aller kraft, nach der Richtung, die diese bekömmt, notwendíg entweder ein Brutus oder ein Catilina zu werden. Unglückliche Konjunkturen entscheiden für das zweite und erst am Ende einer ungeheuren VerIrrung gelangt er zu dem ersten. Falsche Begriffe von Tatigkeit und EinfluB, Fülle von Kraft, die alle Gesetze übersprudelt, muBten..sich natúrlicher Weise an bürgerlichen Verhältnissen zerschlagen, und $z u$ diesen enthusiastischen Träumen von GröBe und Wirksamkeit durfte sich nur eine Bitterkeit gegen die unidealische Welt gesellen, so war der seltsame Don Quixote fertig, den wir Im Räuber Moor verabscheuen und lieben, bewundern und bedauern. Ich werde es hoffentlich nicht erst anmerken dürfen, daB ich dieses Gemälde so wenig nur allein Räubern vorhalte, als die satire des spaniers nur allein Ritter geiBelt. 4

Und in einem Brief an Dalberg schreibt der Dichter folgendes: "Der Räuber Moor, wenn er, wie ich zum voraus versichert bin, seinen Mann unter den $H_{\text {. }}$. Schausplelern findet, dürfte auf dem Schauplatz Epoche machen, einige wenige Speculationen, die aber auch als unentbehrlich Farben in dis ganze Gemälde splelen, weggerechnet, lst er ganz Handlung, ganz anschauliches Leben. " 5 
In der zwelten Szene des Dramas sehen wir den Helden in einer "Schenke an den Grenzen von Sachsen." Er grübelt über die Unzulänglichkelten der Welt nach. Ihn "ekelt vor [dẹ] tintenklecksenden säkulum...." wenn or Im Plutarch von großen Menschen liest. Er findet also die Muster für die große Tat im Altertum. 6 Aus thm spricht die Sehnsucht eines ganzen Geschlechts nach Freiheit und Kraft; die Empörung Schillers über selne unglückliche Jugend bricht mit hervor. Aus dem zwang eine: Uniform- und Kasernensystemsist zu verstehen, was der Dichter durch Karl darstellen will.

Der junge Held sucht die Natur und das Naturhafte. Er beklagt sich über das „Kastraten-Jahrhundert, [das] zu nichts nütze, als die Taten der Vorzeit wiederzukäuen..." Um sich herum sleht er nur veraltete Konventionen, Er 1st enttäuscht; er weiB nicht, was er machen soll. Doch eines 1st klar: er braucht Freiheit. Dieser Kraftmensch rebelliert also gegen das Gesetz. Moor sieht die äuBeren Zustände der Welt an, und bemerkt, daB das Gesetz den Menschen unterdrückt. Wegen des Gesetzes kann der Mensch nicht groB werden. Moor kann keine Einschränkung dulden. Er muB frei sein. Für spiegelberg bedeutet die Freiheit nicht mehr als: dem Gefängnis oder dem Druck der bürgerlichen ordnung entronnen $2 u$ seln. Moor versteht sie aber in einem allgemeineren Sinne. Er revoltlert nicht gegen dieses oder jenes Gesetz, sondern gegen das Gesetz überhaupt. „Das Gesetz hat zum Schneckengang verdorben, 
was Adlerflug geworden wäre. Das Gesetz hat noch keinen großen Mann gebildet, aber die Freiheit brütet Kolosse und Extremitäten aus."

In diesem Zwanzigjährigen lebt die Bewunderung der rein physischen KraftäuBerung. Er sehnt sich nur nach Freiheit, um selne Kraft in der großen Tat zu verströmen. 7 Dadurch verstöBt er aber gegen die bürgerliche ordnung, indem er sie verbessern will. Er berauscht sich an seiner revolutionären Kraft: „Ah! daB der Gelst Hermanns noch in der ABche glimmtel - Stelle mich vor ein Heer Kerls wie ich und aus Deutschland soll eine Republik werden, gegen die Rom und sparta Nonnenklöster sein sollen." $(I, 2)$

Von dem Vorschlag Splegelbergs, Räuber zu werden, lst aber noch nicht die Rede. Karl wendet sich verächtlich davon ab. Der reiche, übermütige funge Mann hat sich früher in Jugendstreichen gefallen. Er hat viele Leute schockiert. Dann haben Schulden thn und seine Genossen aus Leipzig vertrieben. Jetzt aleht er aber diese frühere Torheit ein. "Glück auf den Weg! Stelg du auf Schandsäulen zum Gipfel des Ruhms. In Schatten meiner väterlichen Haine, in den Armen meiner Amalie lockt mich ein edler vergnügen. Schon die vorige Woche hab ich meinem Vater um vergebung geschrieben, hab ihm nicht den kleinsten Umstand verschwlegen, und wo Aufrichtigkeit 1st, ist auch Mitleid und Hilfe." Karl will sein Leipziger Leben also nicht fortsetzen. Er lst der verlorene Sohn, der zurück möchte in 
die Arme des verzelhenden Vaters und des llebenden Mädchens.

Die Veranlassung zum Räuberleben gibt die Verstoßung durch den Vater, mit der die reüütige Unterwerfung des Helden beantwortet wird. Die Llebe des Vaters wäre gleichsam die ,Brücke,' die ihn an das ,Ufer elnes neuen Lebens' hinüberführen sollte. ${ }^{8}$ Moor hat den festen Glauben, daB die Blutliebe heilig ist, ein Gleichnis des Göttlichen. als'. Wenn die ,Brücke' zusammenbricht, und das Heiligste verlorengeht, beginnt die Tragödie. Er bekommt den Brief von seinem Vater. Die ganze innere Existenz Moors beruht auf der väterlichen Liebe. Er liest die Worte und rennt hinaus: der Vater hat thn zurückgestoBen. Diese Nachricht kann er nicht glauben. "Ich hab thn so unaussprechlich geliebtl So liebte kein Sohn, ich hätte tausend Leben für ihn..."

Karl beginnt aber nicht sofort mit seinem Racheverlangen, denn der Schlag hat thn stark getroffen. Kurz danach kehrt er wieder zurück, fast außer sich. Sein wüten beherrscht die Bühne: der Zuschauer sieht den rebellischen EntschluB schon im Voraus. Die Empörung Moors steigt höher und höher.

Spiegelberg schlägt seinen Kameraden vor, daB es das Beste se1, Räuber zu werden. Er gewinnt sle dazu. Man wèiB aber noch nicht, wer der Hauptmann sein soll. Splege1berg bietet sich an. Seine Worte gehen an allen vorbel: 
nur Karl Moor kann Führer solch einer Bande sein. In seiner Raserei ist dieser zunächst taub gegen den willen der Genossen. Dann trifft inn plötzlich der Anruf: er soll Räuberhauptmann werden. Br sleht in diesem Ruf eine höhere Fügung. Was bleibt $1 \mathrm{hm}$ letzten Endes übrig? $\mathrm{Br}$ muB Räuber werden. "Slehe, da fällt's wie der Star von meinen Augen, was für ein Tor 1 ch war, daB ich ins Käficht zurück wolltel- Mein Geist dürstet nach Taten, mein Atem nach Frethe1t, - Mörder, Räuberl - mlt diesem Wort war das Gesetz unter meine FüBe gerollt..." $(I, 2)$ Er läBt sich darauf Treue schwören, und legt selber den Eid ab: „... und bel dieser männlichen Rechten schwör ich euch hier, treu und standhaft euer Hauptmann zu bletben... Den soll dieser Arm glelch zur Lelche machen, der jemals zagt oder zwelfelt oder zurücktritt. Eln gleiches widerfahre mir von jedem unter euch, wenn ich meinen Schwur verletzel"

Karl Moor muB aber die Schranken selner Freihelt erfahren. Er muß auch das Schreckliche erleben, das die Folge seiner Handlung ist. Er ist elgentlich nicht frei in seinem EntschluB. Er wird mehr dazu durch Lage und Affekt genötigt. ${ }^{9}$ Diese Kraftnatur fühlt sich von der Gesellschaft herausgefordert. Sie hat inn verworfen. Er will also die Gesellschaft angreifen, denn sie muB den haBerfüllten Vater motiviert haben. Das gesellschaftliche System hat Schuld an diesem Unrecht. Es wird Moor auf einmal 
klar, daB die Menschhelt, die er früher geliebt hat, nicht mehr existiert. Diese Menschheit, die "heuchlerische Krokodilbrut," hat inn betrogen, und daran wird er seine Rache nehmen. Man hört die Rede eines Rasenden, wenn Moor seinen Schritt auch moralisch rechtfertigen will: "Menschen haben Menschhelt vor mir verborgen, da 1ch an die Menschhelt appellierte; weg dann vor mir, Sympathle und menschliche Schonungl-- Ich habe keinen Vater mehr, Ich habe keine Liebe mehr, und Blut und Tod soll mich vergessen lehren, daß mir jemals etwas teuer war." Moor wird Minister, Finanzräte, Advokaten strafen. Er wird also "die Gerechtigkelt zur feilen Hure" machen. Es macht einen tiefen Eindruck wenn als Karl dem "Menschengeschlecht" den krieg ankündigt. Dennoch besteht die endgültige Frage: was hat elgehtlich das Menschengeschlecht, bzw. die unglücklichen Greise, Weiber, und Kinder, die in einem ruhigen Dorf getötet werden, überhaupt mit einem Vater-Sohn Konflikt zu tun? Es schelnt unerklärlıch, warum der Räuber gewordene Held seine Wut an allen möglichen und unbeteiligten Personen auslassen wird, anstatt nur dem Schuldigen zu Leibe zu gehen. Die fanatische Haltung des rebellierenden Helden muB ideologisch und moralisch begründet werden. Dle Räuber ist vor allem kein psychologisches, sondern ein symbolisches Drama, das elne gewlsse Phantastik des Dramatikers aufwelst. Korff behauptet, daB Schiller seinen Helden 
zum Sozialrevolutionär, zum politischen spartakisten macht. Korff betont das "entscheidende Moment" für diesen Helden. Es wäre also nicht die klare Verstoßung durch den vater, die nur die "negative Vorbedingung" dafür schafft. Das wirklich entscheidende Element auf Seite des Helden bezieht sich auf die phantastische Vorstellung, woran er sich berauscht: er glaubt, der Rächer der verratenen Menschheit werden zu können. In dem Augenblick, wo Karl sich miBhandelt glaubt, erfüllt sich seine phantasie mit allem in der Gesellschaft ausgebrüteten Unrecht. Die Unterarückung der Menschheit zwingt ihn zu seiner Aufgabe: "die Idee der Menschheit gegen die Gesellschaft zu vertreten." 10

Moors Tat, geboren in einem Anfall von Raserei, soll nichtsdestoweniger auf einer bestiminten Ideologie beruhen. Diese Tat wird nicht nur von einem zur Verzweiflung gebrachten Kraftmenschen vollzogen, sondern von einem moralischen Idealisten. Diese Ideologie, durch persönliche veranlagung vorbestimmt, ist aber nur durch persönliches Schicksal reif geworden. Dazu lst sie auch durch eine wahrhaft revolutionäre Gesinnung entzündet: "Rache des Menschen an der Gesellschaft für alle Schändung des Menschen durch die Gesellschaft." 11

Moor glaubt, daB er eine Art neuer Menschheit herviorbringen könne. Seiner Meinung nach wäre gerade er der Mann zu einer so großen Tat. Er fühlt sich von der 
existierenden Menschheit befreit und setzt sein Selbstvertrauen auf die glorrelche Zukunft. „Nun dann, so laBt uns gehn! Fürchtet euch nicht vor Tod und Gefahr, denn über uns waltet ein unbeugsames Fatum! Jeden erellet endlich sein Tag, es sel auf dem welchen Küssen von Pflaum, oder in rauhen Gewühl des Gefechts, oder auf offenem Galgen und Radl Eins davon ist unser Schicksal." $(I I, 2)$ Un sein Ziel aber zu verwirklichen, stellt er fest, daB er zum verbrechertum getrieben wird. Damit begeht er vielleicht den gröBten Irrtum seines Lebens. (Immerhin ist es ein edler Irrtum.) Ein tugendhafter junger Mann, der edle Hoffnungen gehabt hat, gibt also den Glauben auf. Er hat Immer die Menschheit geliebt; jetzt lst er der Menschheit Feind. Paradox scheint es auch, daB der Mensch, der ein Vorbild für die ganze Menschheit hätte sein können, jetzt gegen sie kämpft. Menschheitsliebe verwandelt sich also in MenschheitshaB.

Schlller hat bis zum Ende des ersten Aktes die Prämissen entwickelt, aus denen die tragischen Folgen sich entfalten können. Karl ist auf dem Weg zum Verbrechen, von dem es kein Zurück mehr gibt.

In zweiten Akt werden wir in die "Böhmischen wälder" versetzt, wo Karl und seine Freunde ein ,freies' Leben führen. Aber durch die Bande zleht ein tlefer RIB: ein Teil der Bande, mit splegelberg an der spitze, lüstert nur 
nach Raub, Brandstiftung, und einem zügellosen Leben. Diese Räuber scheuen selbst nicht vor Klosterschändung und Nonnenvergewaltigung zurück. Dagegen geht das streben des Hauptmanns Karl Moor dahin, dem bedrängten Menschen zu helfen. Selne Verbrechen geschehen nicht aus EIgennutz, sondern aus seinem großen Idealismus:

Höre sle nicht, Rächer im Himmell- Was kann ich dafür? Was kannst du dafür, wenn delne Pestilenz, delne Teurung, deine Wasserfluten, den Gerechten mit dem Bosewicht auffressen? Wer kann der Flamme befehlen, daB sie nicht auch durch die gesegneten Saaten wüte, wenn sie das Genist der Hornissel zerstören soll? - o pfui, über den Kinder-Mordl den Weiber-Mord _- den KrankenMord! Wie beugt mich diese Tat! sie hat meine schönsten Werke vergiftet. (II, 3)

Schiller betont selber in seiner Vorrede zum Drama, daB der Held dem Don Quixote sehr nahesteht. Schiller weist mehrmals darauf hin, daB sich Moor "nur" mit Morden abgegeben habe. Und wer sind die Opfer seines Rächeramtes? Er zählt sie dem Pater auf, der als Abgesandter der Gesellschaft vor dem Räuberhauptmann erscheint. Pater Moser glaubt, Moor ins Gewissen reden zu können. Doch atatt des buBfertigen sünders, findet er den zornigen Rächer. "in dessen flammenden Beredsamkeit die christliche Gesellschaft selbst vernichtet wird."12

Als Moor mit der Bande von dem Militär eingeschlossen wird, kommt es zu einem dramatischen Höhepunkt: der Pater bletet den Räubern Generalpardon an, wenn sie den Hauptmann gefesselt ausliefern. Pater Moser: "... So soll euch die Strafe eurer Greuel bls auf das letzte 
Andenken erlassen sein - die hellige Kirche wird euch verlorne Schafe mit erneuerter Liebe in ihren MutterschoB aufnehmen, und fedem unter euch soll der Weg zu einem Ehren-Amt offen stehn ... Frisch alsol Bindet ihn, und seid frell" (II,3) Moor, der ohnedies an der Tragik des Räuberlebens leidet, erklärt sich freiwillig als opfer für alle. Roller begeistert die Bande aber mit dem Anruf: „Und wenn die Hölle uns neunfach umzingelt! Wer kein Hund 1st, rette den Hauptmann." Die Bande bleibt ihrem Führer treu. Der Pater läuft fort. Als aber Karl die rreue zu der Bande wiederholt, geht jede Hoffnung auf ein neues Leben zugrunde. Damit ist der würfel gefallen. "Itzt sind wir fre1- Kameraden! Ich fühle eine Armee in melner Faust- Tod oder Freiheitl wenigstens sollen sie keinen lebendig haben!"

In diesem Sinne ist der Held eigentlich ,blind.' indem er nur eine vage Vorstellung von der Welt hat. Er wird nicht nur von ungestümen Leidenschaften umfangen, sondern von der Macht seines 1ch-bezogenen Willens. Goethe sagt, daB alle Werke Schillers von der Idee der Freihelt durchzogen sind. Doch Schiller unterscheidet scharf zwischen subjektiver und objektiver Freiheit. Seine Helden suchen sie, aber diese Freihelt bezleht sich nur auf das subjekt. Karl Moor wird also weltverbesserer, während Franz sich zum Gottesleugner macht. Leider müssen beide an dieser ,frelen' Existenz scheitern. Das Scheltern führt 
aber Moor zur wahren Freiheit, d.h. "zu dem Akt, durch den [e] sich mit dem willen Gottes wieder in übereinstimmung [setzt]."13 Erst am Ende des Dramas gewinnt Karls Begriff der Freihelt, bis dahin ebenso blind wie seine Augen, zum ersten Mal Inhalt, menschenwürdigen und menschenachtenden Inhalt. ${ }^{14}$

Moor lernt die wichtigete Wahrheit kennen, er lernt die Idee des Selbst gründlich kennen. In den Räubern begegnet sle uns merkwürdigerweise sowohl im Munde des Bösewichts Franz wie des Helden Karl. Franz schuldet sein Leben, aber nicht seine Individualität dem Vater. Und da es eigentlich nur auf das Individuum ankommt, da es nicht auf den Vater zurückgeführt werden kann, achtet Franz nicht auf selne groteske Person.

Man kann auch den Begriff des Ichs im Selbstmordmonolog Karl Moors wahrnehmen. Moor beginnt mit einem Gedanken, der ganz aus der Aufklärung kommt: "Es lst doch elne so göttliche Harmonie in der seelenlosen Natur." Und zwar lst das Barockdrama das Vorbild Sch1llers, indem er barocke Bühnenbilder vor sich sleht. Wlchtig ist es aber, daB er deren Ausmalung der Phantasie des Zuschauers überläßt. ${ }^{15}$

Karl spürt diese Harmonle des Naturhaften. Doch weib er, daB es keine Hoffnung für thn gibt. Mit einer Pistole in der Hand, spielt er gelassen mit Belbstmord- 
gedanken. Wozu sollte er elgentlich Hoffnungen haben? Eine Pistole macht alle Menschen gleich, und setzt Zeit und Ewigkeit in Verbindung miteinander. Moor stellt sich die fürchterlichen Alternativen vor: im Leben gibt es nur die Gefängnisstrafe, die Ihm glelchsam eine owige Nacht bietet. Im Tod kann er auch nichts anderes als eine grausame Nacht erwarten. In diesem verzweifelten Zustand will er wissen: wohln? "Wohin willst du mich führen? --Fremdes, nie umsegeltes Land!" Wie Hamlet, denkt er an den Tod. Aber Moor lst kein Hamlet, sondern, ein junger Deutscher, der nicht imstande ist, seiner sentimentalen und zugleich philosophterenden Epoche entgehen zu können. $\mathrm{DaB}$ er ein kummervolles Leben hat, beschäftigt ihn beständig. Er fühlt sich fluchbeladen, von Gott verlassen.

Bald verwandelt sich aber das Selbstmordgespräch in eine neue Bestätigung des Ichs. Moor findet wieder den Mut, an die Zukunft zu denken, sogar auf sie zu hoffen. Er redet sich ein, daB diese Zukunft eine philosophische Aufgabe sel. Auf die Frage der Existenz, d.h. wozu?, bleibt für Moor nur der Rückzug auf das einzige unverlierbare Gut: Ich selbst- „Sel, wie du willt, namenloses Jenseits - bleibt mir nur dieses mein Selbst getreu- Sel wie du willt, wenn ich nur mich selbst mit hinübernehmeAuBendinge sind nur der Anstrich des Manns- Ich bin mein Himmel und meine Hölle... Und soll 1ch für Furcht eines qualvollen Lebens sterben?- Soll ich dem Elend den 
Sieg über mich einräumen? - Nein! ich wills dulden. Die Qual erlahme an melnem Stolzl Ich wills vollenden." (IV,5) Im Gegensatz zu seinem Bruder also, der aus dem Ich-Selbst das Recht für fede bellebige Tat ableitet, bekennt sich Karl zu seinem Ich als selner Wonne und seinem Fluch, erbebend in der Eingamke1t, aber dennoch mit einem gewissen Triumph. Diese Verachtung der AuBendinge, die nur der Anstrich elnes Menschen sind, erinnert Emil staiger an Leisewitz' Julius von Tarent. Da werden die ,AuBendinge' aufgezählt als Schalen, die das Schickeal abschält, wenn es will. ${ }^{16}$ stalger behauptet ferner, daB sich das "Ich-Selbst" zunächst nur negatıv bestimmen läBt. Es geht in keiner Wirklichkelt auf, in keine ein. Es 1st erhaben über den Raum und auch über die ze1t. Das "Ich-Selbst" duldet keine Einschränkung, weder durch Irgendwelche irdische Macht, noch durch eine höhere Autorltät. Es lst das höchste menschliche Gut: die Fre1heit. 17

Moor hat sich an einem großen ziel entzündet; er lernt sich als Element handelnder und wagender Freiheit kennen. Beim jungen Schiller gewinnt diese Freihelt metaphysische Bedeutung. "Sie 1st wie der Grundzug, der den Menschen zum Menschen macht. Sie führt in Verstrickung und Schuld; durch Freihelt aber erhebt sich der Mensch auch zur sühne."18 
Zuerst leldet Moor an der Verzwelflung, dann bäumt er sich trotzig gegen sein Schlcksal auf. SchlieBlich erfüllt ihn eine tlefe Wehmut, die er über seine verlorene Unschuld ausströmen läBt. Eleglsche Stimmungen werden durch Naturotimmungen begle1tet und zugleich angeregt. Karls hinreiBende Elegie an der Donau beim Sonnenuntergang iot eln Beispiel dafür: "... So stirbt ein Heldl - Anbetenswürdig! Es war mein Lieblingsgedanke, wie [äle Sonne] zu leben, zu sterben wie sie-." Moor blelbt letzten Endes ein Held. Durch erlittenes Unrecht wird Karl zum Verbrechertum getrieben. Aber Schiller läBt die sittliche GröBe des Helden triumphieren. Moor stellt sich der Justiz: "Nicht, als ob ich zweifelte, sie werde mich zeltig genug finden, wenn die obere Mächte es so wollen. Aber sie möchte mich... mit zwang und Schwert umarmen, und dann wäre mir auch das einige verdienst entwischt, da $B$ ich mit willen für sie gestorben bin."

$\mathrm{Zu}$ gleicher zeit lst die Haltung Moors Beweis dafür, daB er überhaupt kein Rebell bzw. keln rebellierender Held sein kann. Ein Rebell trotzt der Autorität, er gibt nicht einfach auf. Moor hat die Gelegenheit, fliehen zu können. Ohne Zweifel müBte er Räuber bleiben, denn er lst ja in dem Räuberleben tief eingewurzelt. Moor verzichtet auf die frele Existenz eines Räubers. Statt dessen stellt er sich freiwilligg der Herr- 
schaft des Staates. "Ich erinnere mich, einen armen Schelm gesprochen zu haben als ich herüberkam, der im Taglohn arbeitet und eilf lebendige Kinder hat. Man hat tausend Louisidor geboten, wer den groBen Räuber lebendig liefert- dem Mann kann geholfen werden." $(v, 2)$

Einerseits scheint es ein Beispiel der persönlichen Entsagung zu sein: daß dieser Mensch Răuber ist, ist klar; daß aber dieser Räuber Mensch ist, folgt nicht. Moor sieht also $1 \mathrm{in}$, daB er das unbeschränkte Leben eines Rebellen fortsetzen könnte, aber auf Kosten seiner Menschlichkeit. Deswegen gibt er schlieblich auf, um dem schon unvermeidlichen Ende $z u$ entgehen.

Andererseits wird die persönliche Entsagung $z u$ einem gröBeren problem: Moor erfährt, daB er sich irrte. Er wollte die Ungerechtigkelten der Welt gewaltsam umstoBen. Das list nicht möglich:

o über mich Narren, der ich wähnete die Welt durch Greuel zu verschönern, und die Gesetze durch Gesetzlosigkeit aufrecht $z u$ halten. Ich nannte es Rache und Recht - Ich maBte mich an, o vorsicht die Scharten deines schwerts auszuwetzen und deine Parteilichkeiten gut zu machen - aber o eitle Kinderei - da steh ich am Rand eines entsetzlichen Lebens, und erfahre nun mit zähnklappern und Heulen, das zwei Menschen wie ich den ganzen Bau der sittiichen Welt zu Grund richten witrden. Gnade - Gnade dem Knaben, der Dir vorgreifen wollte - Dein eigen allein ist die Rache, Du bedarfst nicht des Menschen Hand. Freilich stehts nun in meiner Macht nicht mehr die Vergangenheit einzuholen - schon bleibt verdorben, was verdorben ist - was ich gestürzt habe steht ewig niemals mehr auf - Aber noch blieb mir etwa: übrig, womit ich die beleidigte Gesetze versöhnen, und die miBhandelte ordnung wiederum hellen kann. sie bedarf eines Opfers - Eines Opfers, das thre 
19

unverletzbare Majestät vor der ganzen Menschheit entfaltet - dieses Opfer bin ich selbst. Ich selbst muB für sie des Todes sterben. $(v, 2)$

Wir müssen mit seinem verirrten Idealismus

sympathisieren. Verbrecher ist er, aber menschlich

wertvoller als die scheinhellige Gesellschaft. Ein Ideal.

der Freiheitsdrang, wird durch diesen Räuber verherr11cht. Der erste Versuch Sch111ers, diesen Charaktertyp darzustellen, verherrlicht einen Jungen Menschen, der ofch mit der Welt auselnandersetzt. 


\section{DRITTES KAPITEL}

\section{FERDINAND}

Kabale und Liebe ist 1783 geschrieben worden. während dieser Zeit befand sich schiller in innerer. sowohl wie in äuBerer Gefährdung. Kaum hatte er mit einigen Dramen begonnen, die thm endlich Ruhe und Sicherheit bringen sollten, da wurde er von einer schweren Krankheit befallen. Diese Art Influenza machte thn wochenlang arbeitsunfähig, und beunruhigte ihn den ganzen Winter hindurch. Er muBte einen erschöpften Körper bekämpfen, um jetzt das Werk (Kabale und Liebe) hervorbrıngen zu können.

Der Kampf gegen eine physische Belastung gilt für sein ganzes Leben. Wie in einer Vorahnung, schrieb er an Frau von Wolzogen: er fürchte, daB ihm dieser Winter vielleicht einen tödlichen sto $B$ versetzt habe. Dennoch scheint er dem miBgünstigen schicksal zu trotzen. Im Januar 1784 wurdefiesco aufgeführt- erfolgreich, wenn auch nicht so erfolgreich wie Dle Räuber. Schiller meinte: "In den Adern der Pfälzer fließt kein römisches Blut." 1 Kabale und Liebe findet ihre Uraufführung kurz darauf, am 13. und 15. Apr11 in Frankfurt und Mannhe1m. Die Wirkung dieses stückes war ohne Zwelfel sehr groB. 
Kabale und Liebe war eines der ersten Theaterstücke, indem ein deutscher Dichter sich mit den sozialen Fragen seiner Gegenwart auseinandersetzt. Emilia Galotti, das bürgerliche Trauersplel Lessings, bezieht sich auf eine ähnliche situation, Doch sie ist enger und enthält nicht die hinreiBende Faszinterung, die Schlller iervorbringt. Lessing befasst sich mit einem Kampf zwischen bürgerlicher sittlichkelt, und höfischer Intrige. Der Aufklärungsdichter hatte sich aber von dem Zuschauer distanziert, denn dieses Drama findet in einem anderen Land, und in einer anderen zeit statt. Schillers Sturmund Drangstück dagegen machte einen tiefen Eindruck auf seine Zeitgenossen. Sie konnten sich leicht mit dem Thema Identifizieren.

Nirgendwo in der deutschen Literature des achtzehnten Jahrhunderts ist der Konflikt zwischen Staatsgesetz und menschlichem Glück mit solcher stärke geschildert worden. Eine Auseinandersetzung zwischen staatlicher Willkür und menschlicher Freiheit ist die beste Feststellung dieses Jugendwerkes Schillers.

Ferdinand, der Junge Idealist des Dramas, 1st der Sohn des Präsidenten von Walter. An dem Hof eines deutschen Fürsten besteht keine Möglichkeit einer freien Handlung. Darum fühlt sich der Held bedrängt. Er hat sich aber in ein' Mädchen verldebt, das' aus dem Bürgertum stammt: 
Luise ist die Tochter eines Stadtmusikers. Und obgleich der Standesunterschied dor Gellebten betont wird, gibt es dennoch eine, wahre Liebe' zwischen beiden. Sle können aber den höfischen Normen nicht entfliehen. Diese Macht erweist sich als unentrinnbar. Es lst eine Macht, die den Menschen selber vernichten kann.

Ferdinand 1st Vertreter einer jungen Generation. Er kämpft gegen die absolute Autorität des Hofes. Auf die Erfüllung seiner Liebe bedacht, wird er in einen Kampf mit ständischen Ansprüchen verwickelt. ${ }^{2}$ von vorne herein hat Schiller die tragische Lage des Liebespaares beschrieben. Der Vater steht seinem Sohn gegenüber, und behandelt inn mit entschlossenem Willen. Im Leben Ferdinands herrscht also die Liebe; im Hofleben herrscht die Kabale. In der Welt des Hofes, die der Präsident verkörpert, scheint das Intrigenspiel die überlegene stellung 24 gewinnnen. Ferdinand handelt ganz nach seinem Herzen. Er hängt vielleicht weniger von seinem vater und dessen politischer Macht ab, als der Zuschauer glauben möchte. Der Präsident und Ferdinand sind Gegenspieler, aber der Jüngere ist berelt, ohne Hemmung fedem höfischen Plan entgegenzutreten. ${ }^{3}$ Das Verhältnis zwischen vater und Sohn bezelchnet also keinen Lebenszusammenhang, sondern nur eine dramatische Funktion, die am SchluB dieser Untersuchung analysiert werden wird.

Der liebende Ferdinand gehört In die Rethe der 
Schillerschen Helden. Er zeigt sein eifersüchtiges Temperament schon bei seinem ersten Auftritt $(I, 4)$. Ohne den geringsten Grund dafür macht er sich Sorgen, ob Luise thn noch liebt. Er behauptet, daB seine "gestrige Liebe" Immer noch bestehe und fragt Luise, ob sie dasselbe Gefühl für thn habe. Sein Benehmen kennzeichnet vor allem eine schwärmerische Natur. Immer wieder, wenn er allein mit ihr 1st, neigt or zu dem Liebeszweifel. Luise iat aber ganz von einer großen und reinen Liebe $z u$ Ferdinand erfüllt. Sie ist aber auch verzweifelt: sie glaubt, daB sie kein glückliches Leben haben kann. Sle liebt den Adligen, und möchte dieses Glück nicht aufgeben. Doch weik sie, daB selbst das gröBte Bekenntnis der Liebe die strengen Sozialgesetze nicht aufheben kann: „Du willst mich einschläfern, Ferdinand- willst meine Augen von diesem Abgrund hinweglocken, in den ich ganz gewiB stürzen muk. Ich seh in die zukunft- die stimme des Ruhms- deine Entwürfe- dein Vater- mein Nichts. Ferdinand! ein Dolch über dir und mirl Man trennt uns!" $(I, 4)$ Luise hat schon mit ihrem vater gesprochen, und die Tatsache bleibt unverkennbar: sie darf den Gellebten nicht heiraten. Sie muB Ferdinand entsagen.

Luise ist von dem Beginn der Handlung bis zum Ende bereit, auf Ferdinand zu verzichten. Sle begrenzt aber ihren Verzicht, indem sie sagt: "Ich entsag thm für dieses Leben." Sie benimmt sich als das bürgerliche Mädchen, 
das dem Geliebten nicht folgen kann. Sie vertröstet sich mit der Idee eines jenseitigen Lebens, wo "die Schranken des Unterschieds einstürzen, von uns abspringen all die verhaßten Hülsen des standes, und Menschen nur Menschen sind." $(I, 3)$

Miller, ohne eigentlich einen Befehl zu geben, bringt Luise zu inrer Entscheidung. Luise hat aber nicht auf einmal die Wahrheit ihres bürgerlichen standes erkannt. Dieser Keim wächst schon in dem kleinen Kind. Je älter es aber wird, desto peinlicher wird die bedrängte Lage. Der Mensch kann versuchen, den Klassenunterschied zu übersehen. Er kann sich einfach mit einer erträglichen Tatsache des Lebens abfinden. Luise konfrontlert also die Unbedingtheit threr persönlichen Lage und scheint imstande, die richtige und auch praktische Lösung zu treffen. Luise lst in einem bürgerlichen Hause aufgewachsen, in dem das Gesellschaftssystem schon lange akzeptiert worden 1st. Ihre Entsagung in der dritten Szene entspricht also dem zornigen Ton ihres Vaters in der ersten. Hier drückt Miller seine resignierte stellung deutlich aus. Empört weist er auf die verbindung zwischen seiner Tochter und dem Sohn des Präsidenten hin. Er stellt sich nur die schrecklichsten Auswirkungen vor, käme eine so skandalöse Ehe zustande. Er hält es daher für geraten, Seine Exzellenz, den Vater Ferdinands, wissen zu lassen, daB seine Tochter nzu schlecht zu Dero Herrn Sohns Frau [Boi, ihm aber] zu 
Dero Herrn Sohns Hure zu kostbar, und damit basta." Vor allem schätzt der stadtmusiker das Wohl seiner eigenen Familie. Im Licht der unübertretbaren Gesetze des Standes weiß er eines: er wünscht, seine Tochter hätte den Major nie getroffen. Ferdinand ist eine enorme Bedrohung, denn er stört das gesellschaftliche Gleichgewicht durch sein ungestümes, rebellierendes Verhalten. Da Luise den

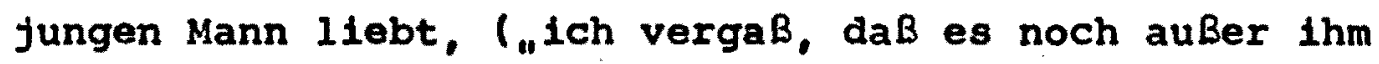
Menschen gibt..."), muB diese heikle situation möglichst bald beseitigt werden. Miller reaglert fast intuitiv, denn wie Luise, lst auch thm das klassensystem gründlich belgebracht worden. "NImm meinen alten mürben kopf- nimm alles-alles! den Major- Gott 1st mein Zeuge- ich kann dir ihn nimmer geben." $(I, 3)$ Er fasst den Helden also nicht als Menschen auf, der menschliche Eigenschaften besitzt. Dieser verängstigte vater versteht Ferdinand oher als Symbol der staatlichen Herrschaft. Während Luise und ihr vater bereit sind, ihre Umwelt realistisch zu akzeptieren, erweist sich Ferdinand als unerschrockener Idealist. Darin besteht der tragische Konflikt dieses Dramas.

Alle Mitglieder der bürgerlichen Familie stellen sich mehr oder weniger auf die Seite einer Entsagung. Von solch einer unterwürfigen Reaktion 1st Ferdinand aber weit entfernt:

Ich bin ein Edelmann... Wer kann den Bund zweier Herzen lösen oder die Töne elnes Akkords aufein- 
andorreiBen?... LaB doch sehen, ob mein $\Lambda$ delbrief äter ist als der RiB zum unendlichen Weltall? oder mein Wappen gültiger als die Handschrift des Himmels in Luiseng Augen: Dies Welb ist für diesen Mann? - Ich bin des präsidenten Șohn. Eben darum. Wer als die Liebe, kann mir die Flüche versüßen, die mir der Landeswucher meines Vaters vermachen wird.

Wichtig lat es für diesen stürmer, daß die Rechte des Individuums erhalten werden. Seines Erachtens nach, 1st der Mensch ein Wesen, das über jeder Irdischen Begrenzung steht, d,h. über dem Gesetz des Klassenranges. Wichtig 1st, daB Ferdinand, ein Adliger, die künstliche scheidewand zwischen den ständen in Frage stellt. Seine groBe Leidenschaft kennzeichnet nicht nur den Kampf um eine freie Gattenwahl, sondern um elne völlig ldealistische Weltanschauung. 4 Der rebellierende Ferdinand bildet sich eln, or kann der geordneten Welt elnfach trotzen. Er fürchtet nichts, und verteidigt vor seiner Geliebten die Untrennbarkeit Ihrer Liebe. Er wird Luise vor jeder Drohung schützen.Er hält die fantastische Überzeugung, daB es überhaupt keine Macht gäbe, die er nicht besiegen könnte. Er schreckt sogar nicht vor dem höheren Schicksal zurück; dessen widrige "stürme... sollen meine Empfindung emporblasen, Gefahren werden meine Luise nur reizender machen."

Also nichts mehr von Furcht, meine LiebeIch w11l über dir wachen wie der Zauderdrach über unterirdischem Golde- Mir vertraue dich. Du brauchts keinen Engel mehr Ich will mich zwischen dich und das Schlcksal werfenempfangen für dich jede Wunde- auffassen $f \ddot{u} r$ dich jeden Tropfen aus dem Becher der Ereude- 
dir thn bringen in der Schale der Liebe. $(I, 4)$ Der menschlichen Liebe gegenüber steht die noch menschlichere Kabale. Präsident von Walter will zuerst nicht an ein "ernsthaftes Attachement" seines Sohnes an die "Bürgerkanatlle" glauben. Er hat ganz andere Pläne: der Hèrzog"sucht eine Partie für seine Favoritin, die Lady Milford, und Ferdinand soll thr Gatte werden. Der Präsident hofft dadurch, den Herzog zu verpflichten: "... Ein anderer kann 8 ich melden- den Kauf schließen, mit der Dame das vertrauen des Fürsten anreiBen, sich ihm unentbehrlich machen!- damit nun der Fürst im Netz meiner Famille bleibe, soll mein Ferdinand die Milford heiraten." (I,5) Ehe er also mit Ferdinand gesprochen hat, läßt der Präsident eine sensationelle Neuigkeit herumgehen: Lady Milford soll die Majorin von Walter werden.

Im letzten Auftritt dieses Aufzugs treffen sich Vater und Sohn. Der Realist steht dem Idealisten gegenüber. Der Präsident verläBt sich auf den mächtigen zwang, auf die totale Herrschaft. Ferdinand hat sich dagegen der Freiheit ergeben. Solche kontrastierenden Gestalten können nur einen unwirklichen Elndruck aufeinander machen. Keiner versteht die wirklichen Motive des anderen. Die zwei Männer sind Gegenspleler, aber sie wissen nicht, worauf sie zielen sollten, um den Gegner zu besiegen. Die Aussprache mit Ferdinand führt also zu 
einer heftigen Auselnandersetzung. Für den Präsidenten 1st der Aufstand des Sohnes elne überraschung. Wahrscheinlich kannte er diesen Sohn nicht so gut, wie er glaubte. Auf Jeden Fall welgert slch Ferdinand standhaft, die "privileglerte Buhlerin" zu heiraten. Der Vater will thn aber nochmals prüfen; er schlägt Ferdinand also elne andere Helrat vor, und zwar mit elner Dame des Hofes mit untadeligem Ruf. 5 Dieser Vorschlag wird gleichfalls abgelehnt. Am Ende schleudert er Ferdinand die Drohung entgegen: "Wenn Ich auftrete, zittert ein Herzogtum. LaB doch sehen, ob mich ein Starrkopf von Sohn meistert." Wegen dieses, Befehls' sucht Ferdinand die Lady Milford auf, aber nicht, um um sle zu werben. Als Ehrenmann will er thr ins Gesicht sagen, $d a B$ er sie verachtet. 6 'Er glaubt, der Britin einen Spiegel vorzuhalten, ihr die Moralbegriffe eines jungen Deutschen zu zeigen.

Ja! ich will zu ihr- will hin-will ihr einen Spiegel vorhalten- Nichtswürdigel und wenn du auch noch dann meine Hand verlangstIm Angesicht des versammelten Adels, des M111tärs und des Volks- Umgürte dich mit dem ganzen Stolz deines Englands- Ich verwerfe dichein teutscher Jungling! $(I, 7)$

Doch in Lady Milford lernt er keine "Abenteuerin" kennen, sondern eine edel empfindende, von dem Schicksal schwer geschlagene Waise fürstlichen Geblüts. Sie ist wirklich die "freigeborene Tochter des frelesten Volkes unter dem Himmel." BloBer Zufall hat sie zu der Favoritin des Herzogs gemacht. Aus elgener Kraft möchte sie die Ehe- 
partnerin werden. Sie bekennt, daB sie eine echte Liebe nur einmal empfunden hatte und zwar zu Ferdinand: "Und jetzt kommt der Mann, der allein mir das alles belohnen sollte- der Mann, den mein erschöpftes Schicksal vielleicht zum Ersatz meiner vorigen Leiden schuf- der Mann, den ich mit brennender Sehnsucht Im Traum schon umfasse." (II,3) Die geplante Verbindung ist also nicht ein Werk der Hofkabale, sondern ihrer Llebe. Sie erklärt, daB sie diese Ehe mit $1 \mathrm{hm}$ schon lange wünschte, um endlich ein glücklicheres Leben beginnen zu können. Ihrem offenen Geständnis setzt Ferdinand sein eigenes entgegen: "Ich liebe Mylady, liebe ein bürgerliches Mädchen." Dle Engländerin sagt prophetisch voraus, daB, wenn es so ist, dre1 Menschen dadurch zugrunde gerichtet würden, d.h. er, sie, und "noch eine Dritte..."

$\mathrm{zu}$ den schon bestehenden Gefahren tritt also eine neue auf. Jetzt sieht sich Ferdinand einer eifersüchtigen Frau gegenüber, einer gleichsam neuen Feindin, die gefährlich werden könnte.

Von dem Palais der Lady Milford begibt sich der Held Ins Haus seiner Gellebten. Er stürzt erschrocken, auBer Atem, Ins Zimmer. Er kann das Gespräch, mit Lady Milford nicht vergessen. Sie hat ihn vor dem präsidenten gewarnt, daB er slch dagegen wehren sollte. Und jetzt 1st Ferdinand bei Luise und hört noch deutlicher, daB eine große Gefahr für die Liebenden bevorsteht. Während 
Ferdinand seine Gegenwart bel inr preist, äuBert Lulse eine erschütternde Wahrhe1t: sle klagt, Ferdinand töte sie in dieser schrecklichen Stunde. Verblüfft sleht er sie an. Er lst fast außer sich, well er seine übermäßige Leidenschaft nicht beherrachen kann. „Elne Stunde, Luise, wo zwischen mein Herz und Dich eine fremde Gestalt sich warf - wo meine Llebe vor meinem Gewissen erblaßte-wo meine Luise aufhörte, Ihrem Ferdinand alles zu sein- (II,6) Luise erfährt, daB Ferdinand zu einer verbindung hingetrieben wird. Bei diesem Zugeständnis kann sich Ferdinand nur der "Unglückselige" nennen. Was bleibt inm also jetzt übrig? Das, was Luise als unwirklicher Traum vorkommt, wird dem Schwärmer auf einmal sonnenklar: er muß den Kampf mit den Intriganten aufnehmen. Nur dadurch kann die Wahrheit endlich ans licht gebracht werden. Gegen die rührende Geschichte Lady Milfords hat sich Ferdinand als hilflos erwlesen. Jetzt scheint er aber völlig imstande, an das problem heranzukommen. Voll Entschlossenhe1t will er die "Kabalen durchbohren- durchreiken will [er] alle diese elsernen Ketten des Vorurtells. - Frei wie eln Mann will [e] wählen, daß diese Insektenseelen am Riesenwerk [seiner] Liebe hinaufschwindeln." Er will also frei handeln, sein eigenes Leben gestalten. Er zelgt auch elne Ideologie, die Luise schon geäuBert hat: er deutet auch auf die "verhaßten Hülsen des Standes." Seine Auffassung unteracheldet sich aber von ihrer, Indem 
er das Vorurteil sofort abschaffen will. Lulse Miller findet sich mit den Ungerechtigkeiten der sozlalen Struktur ab. Sie akzeptiert ihre unglücklichen verhältnisse: "Vater, hier lat deine Tochter wlederVerzeihung Vater- Dein Kind kann ja nicht dafür, daB dieser Traum so schön war, und —— so fürchterlich jetzt das Erwachen- - (II,6) Ferdinand dagegen 1st nur glücklich, wenn er gegen das unumgängliche kämpfen kann.

In der nächsten Szene kommt es zu einer Begegnung der zwel Familien: Präsident von Walter erscheint in der Wohnung Millers. Um selne endgültige Macht zu beweisen, um den Sohn also zur vernunft zu rufen, läBt der Präsident den wütenden Musiker ins zuchthaus bringen und die Mutter, zusammen mit ihrer "Metze von Tochter" an den Pranger stellen. "Die Gerechtigkeit soll meiner Wut ihre Arme borgen. Für diesen Schimpf muß ich schreckliche Genugtuung haben-Ein solches Gesindel sollte meine Plane zerschlagen, und ungestraft Vater und Sohn aneinander hetzen?... Ich will meinen $\mathrm{HaB}$ an eurem Untergang sättigen, die ganze Brut, Vater, Mutter und Tochter, w1ll ich meiner brennenden Rache opfern." (II, 6) Ferdinand muB sich gegen diesen Gegner anders verteldigen. "Kein menschliches Mittel $11 \mathrm{eB}$ ich unversucht- ich muB zu einem teuflischen schreiten." Ferdinand zwingt den Vater zu einem Rückzug, indem er droht, in der stadt klar- 
zumachen, wie der Vater elgentlich Präsident geworden 1at. Nerkwürdigerwelse ist diese Drohung erfolgreich. Luise und thre Mutter werden frelgelassen, und der präsident zieht slch schnell zurück; Schiller notiert, "wle vom Blitz gerührt."

Daraufhin will Ferdinand den nächsten schritt tun. Er w111 zusammen mit Lulse fliehen. Ferdinand 1st kein Felgling; er will aber den schon gefährlichen Erelgnissen möglichst bald entgehen. Luise hört ihn mit ernster Miene an, zögert aber. Während er thre gemeinsame Llebe verteldigt, stẹltt Lulse diese universale Macht plötzlich In Frage: "Und hättest du sonst kelne Pflicht mehr als deine Liebe?... So schwelg und verlaB mich- Ich habe einen Vater, der kein Vermögen hat, als diese elnzige Tochter- der morgen sechzig alt wird- der der Rache des Präsidenten gew1B 1st.- -

In der vierten Szene will er dem Hofleben entfliehen, denn sein Vater ist immer noch elne drohende Macht, der sich bestimmt nicht gerne erpressen läBt. Ferdinand gab zu erkennen, daB der Aufatieg zum Präsidentenamt durch skrupellose Taten erfolgte. Deswegen war der Vater gezwungen, dem Sohn nachzugeben. Ferdinand lot aber nicht in jedem sinne unvernünftig. Er weiB, daB sein machthabender Vater über welt drohendere ,Kampfmittel' verfügt. Am besten wäre also eln rascher Abschled: "Ich gehe, mache melne Kostbarke1ten zu Geld, erhebe summen auf 
meinen Vater. Es ist erlaubt, einen Räuber zu plündern, und sind seine Schätze nicht Blutgeld des Vaters? Schlag ein Uhr um Mitternacht wird ein Wagen hier anfahren. Ihr werft euch hinein. Wir fliehen." (III,4) Ferdinand ist eine sehr elfersüchtige Gestalt. Als Luise mit ihm nicht fliehen will, gerät er in wut. Auf einmal verwandelt sich seine liebevolle Natur in eine völlig lleblose. Ohne zu wollen, wird ex Opfer seines Egoismus. Oft sagt er, daB er Luise über alles auf der Welt liebt. Das stimmt aber scheinbar nicht, denn er schenkt thr letzten Endes kein liebendes Vertrauen. Sobald er ihr zögern sleht, glaubt er, dessen Grund zu wissen: es gäbe einen anderen Liebhaber: „Schlange, du lügst. Dich fesselt was anders hier... Kalte Pflicht gegen feurige Liebel - Und mich soll das Mädchen blenden? Ein Liebhaber fesselt dich, und weh über dich und ihn, wenn mein Verdacht sich bestätigt." Luise will aber nur einen Klassenstreit vermeiden. Ihre Absichten sind rein. Ganz genau weiB sie die Folgen threr Llebe zu dem Adligen. Nur hofft sie kurze zelt, sle könne beldes behalten, ihren Geliebten und zugleich das ruhige Leben. Es wird thr aber klar, daB in diesem Leben belde Hoffnungen unerreichbar sind. Deshalb trifft sie die Entscheidung, die am geringsten schaden kann: sie entsagt Ferdinand. Dann werden Vater und Sohn, und Vater und Tochter wiedervereinigt. 
Ferdinand sieht das nicht ein. Er hat nur ein ziel vor sich, und dieses 1st Immer auf das ICh-Selbst gerichtet. Seine Ungeduld, sein Kampfgeist lassen jetzt ein vernünftiges Abwarten nicht $z u$. Sein Handlungstrieb und seine opferbereltschaft schlagen um in den absurden Zweifel an Luises Treue. ${ }^{7}$ Es gibt keinen konkreten Beweis dafür, aber Ferdinand glaubt sich betrogen. In dem Sinne 1st or eine konsequente Figur, denn der elngetroffene Erpressungsbrief von Luise bestätigt selnen zornigen Zwelfel. Überzeugt wird er schlleBlich, daB Hofmarschall Kalb die Ursache der Untreue ist. Selbst als dieser die Wahrheit des Ränkesplels später enthüllen will, läBt FerdInand keine Erklärung zu. Das ist wiederum konsequent. Er w11l die Wahrheit nicht hören; er 1st ein Idealist und will nicht von der ,realen Welt' wissen. Das einzige, was sein übermäBiges Temperament geniessen will, lst das Hinaufstelgen zu seiner elgenen Lebensauffassung. Es ist aber schließlich nur eine Traumvision, die nie verwirklicht werden kann.

Interessant 1st, daB Ferdinand ein Ebenbild seines Vaters 1st. Der Präsidentensohn und sein Vater streben nach entgegengesetzten zielen; sle lelden aber an dem selben zerstörenden Egolsmus. Ferdinand: "Ich bin es. Du bist es auch. Ja bel dem großen Gott! Wenn ich verloren bin, bist du es auch! - Richter der Welt! Fordre ste mir ntcht ab. Das Mädchen lst mein! Ich einst ihr Gott, jetzt 
thr Teufell" (IV,4) Belde glauben, sie verfügen über besondere Vorrechte, die unbestritten sind. $\mathrm{Zu}$ spät lernen diese irrenden Menschen die Wahrheit. Sle müssen erfahren, daß dem Menschen die Freiheit auf der Erde nur auf tragische Weise geschenkt wird.

Im Wahn der Untreue Luises schüttet Ferdinand Gift in ihre Limonade. Daraufhin trinken die zwei Liebenden davon. Erst als Luise stirbt, erkennt er das Intrigenspiel. Lelder kann aber nichts getan werden, um die Tragödie abzuwenden. Alles ist fetzt vorbel. Der einzige Trost wäre: die junge Menschen werden den bestehenden Ungerechtigkeiten der Welt entfliehen. Auch tröatend viellelcht ist die Wirkung Ferdinands auf die Welt. Ferdinand 1st der Grund dafür, daß sich der Präsident an Ende des Dramas gefangengibt. Tatsächlich hat er den ursprünglichen Konflikt selber herbelgeführt, Indem er luise von Anfang an in Gefährdung setzte: er hätte sie aufgeben sollen, um einen tragischen Ausgang zu verhüten. Das hat er aber nicht getan; vielleicht war der Liebestrieb zu stark, vielleicht seine willenskraft zu schwach. Das läßt sich nicht feststellen.

Darüber hinaus kann gesagt werden, daB Ferdinand nicht nur eine negative Rolle spielt. Abgesehen von seinen selbstsüchtigen Motiven kann er auch positiv aufgefasst werden, denn er hat sich der ungerechten Welt aufgeopfert. 
Ferdinand 1st 1mmerhin ein Mensch, der Selbstmord begeht. Solch eine irrationale Tat entspricht keineswegs dem Charakter eines Rebellen. Auf diese Weise gibt der wahre Rebell nicht auf. Statt dessen würde er weiterhin kämpfen, weiterhin sein ziel erstreben. Der Grund dafür, warum Ferdinand den elgenen Tod wählt, 1st ein konpl1ziertes Problem. Noch komplizierter ist aber die Bestimmung seiner Gestalt in konsequenter Form. Eine Untersuchung seines rebellierenden oder nicht rebellierenden Gestalt wird in der Zusammenfassung unternommen. 


\section{VIERTES KAPITEL}

\section{DON CARLOS/MARQUIS POSA}

Mit Don Carlog errelchte Schiller zum ersten Mal die klassische Form. Es ist das erste Versdrama, das er schrleb. Dichter vor Schllier hatten schon den fünffüBigen Jambus, den Blankvers, gebraucht. Diese Form war, dem Beispiel Shakespeares folgend, in die deutsche Dlchtung eingeführt worden. Unter anderen sind Brawes Brutus, Wielands Johanna Gray, und Klopstocks Salomo um die Mitte des achtzehnten Jahrhunderts erschienen, Werke Im fünffüBigen Jambus. Aber erst Lessings Nathan der Weise. Goethes Iphigenie, und Schillers Don Carlos haben den Blankvers zum kennzelchenden Vers des deutschen klassischen Dramas gemacht.

Schiller hat an diesem Werk mehr als vier Jahre gearbeitet, von 1783 bis 1787 . Wăhrend dieser zeit erfuhr der stoff strukturelle Verwandlungen, die auch im endgültigen Drama ihre spuren hinterlassen haben. Während der vier Jahre entwickelte sich Schiller von dem "Dichten und Denken seiner Jugend [in die] Reife seines Mannesalters." 1

\section{Die lange Entstehungszeit des Don Carlos wird von} Schiller beurteilt: 
Der Hauptfehler war, ich hatte mich zu lange mit dem stücke getragen; ein dramatisches Werk aber kann und soll nur die Blüte eines einzigen Sommers sein. Auch der plan war für die Grenzen und Regeln eines dramatischen Werks zu weitläuflg angelegt. Dieser plan.z. B. forderte, daß Marquis Posa das uneingeschränkteste vertrauen Philipps davontrug; aber zu dieser auBerordentlichen Wirkung erlaubte mir die ökonomie des stücks nur eine einzige szene. 2

Um 1783 wollte Schiller die Inquisition und "deren Schandtaten" enthüllen. Er hatte auch vor, "die prostituierte Menschheit" rächen zu wollen. 3 Aber unter der Elnwirkung der Leidenschaft für Charlotte von Kalb, tritt das tragische Liebesdrama plötzlich in den Vordergrund. Diese erste Stufe, der "Bauerbacher Entwurf," zielte allerdings weniger gegen die Inguisition als auf eine Familien- und Liebestragödie in elnem fürstlichen Hause. Der Akzent liegt also auf der unerlaubten Liebe des Prinzen zu seiner stiefmutter, deren „lelseste ÄuBerung, Verbrechen" 1st. " Eine Rebelilon des. Prinzen war nur ein Nebenmotiv. Marquis Posa tritt wohl schon auf und ist bereit, sich für Carlos zu opfern, aber nur aus Gefühlen der Freundschaft, nicht wegen einer idealistischen Idee. Posa 1st noch nicht der Erzieher Carlos' zum Idealen Thronfolger in Spanien. 5

Schiller wollte zuerst kein "politisches stück" schreiben, sondern eine Tragödle, die "die schreckliche Situation elnes Sohnes, der ... ohne Hoffnung liebt und endlich aufgeopfert wird." Auch an Dalberg, den Intendanten des Mannheimer Theaters schrieb Schiller: 
Ich bin jetzt mehr als jemals über mein neues Schauspiel verlegen. Woher ich nur Briefe bekomme, dringt man darauf, ich möchte ein großes historisches Stück, vorzüglich meinen Karlos zur Hand nehmen, davon Gotter den Plan zu Gesicht bekommen, und groB befunden hat. Freilich ist ein gewöhniliches bürgerliches sujet, wenns auch noch so herrlich ausgeführt wird, in den Augen der großen, nach außerordentlichen Gemälden verlangenden welt niemalen vọn der Bedeutung, wie ein kühneres Tableau, und ein Stück wie dieses erwirbt dem Dichter, und auch dem Theater dem er angehört schnellern und größeren Ruhn, als drei Stucke wie Jenes. Von Ewr. Exzellenz erwarte ich einen ernsthaften Rath zu meiner letzten Entschließung, welches sujet Ich wählen sol136

Wie weit der Dichter diesen Entwurf ausarbeitete, welB man nicht, denn nichts ist davon erhalten. Erst nach der Übersiedlung nach Mannheim, In Jul1 1783, erfährt das Drama die entscheidende veränderung in der sogenannten "Thalia-Fassung." Erst dann werden die gröBten Themen sichtbar, nämlich Freiheitssinn, Despotismus, Vorurteile, Menschenrechte, republikanische Tugenden:

Carlos 1st ein herrliches sujet, vorzüglich für mich. Vier große Karaktere, beinnahe von gleichem Ưmfang, Karlos, Philipp, die Königin, und Alba offnen mir ein unendliches Feld. Ich kann mir es jetzt nicht vergeben, da $B$ ich so eigensinnig, vielleicht auch so eitel war, um in einer entgegengesetzten Sphäre zu glänzen, meine Phantasie in dife Schranken des bürgerlichen Kothurns einzäunen zu wollen, da die hohe Tragödie ein so furchtbares Feld, und für mich, mochte ich sagen, da ist; da ich in diesem Fache größer und glängender erscheinen, und mehr Dank und Erstaunen wirken kann, als in keinem andern, da ich hier vielleicht nicht erreicht, im andern übertroffen werden könnte; froh bin ich, daB ich nunmehr so ziemlich Meister über den Jamben bin; Es kann nicht fehlen, daß der vers meinem Karlos sehr viel würde und Glanz geben wird. 7

Für solch eln neues Schema müBte Posa elne gleichfalls 
neue Rolle bekommen. Jetzt wird er zum Erzieher des Prinzen in menschlicher sowohl wie in politischer Hinsicht. Diese Wandlung verrät schon der erste Akt der neuen Fassung. Bel seinem Abschied aus Mannheim im April 1785, lieB Schiller diesen Teil im ersten Heft der von Ihm begründeten Zeitschrift "Rheinische Thalla" veröffentlichen. Darauf erscheinen im Februar 1786 der zweite und dritte Akte dieser Thalia-Fassung. Im Grunde genommen entsprechen diese Aufzüge bereits dem endgültigen Werk, obgleich der strelt zwischen den Machtträgern der Kirche und dem Prinzen, in der letzten Fassung stärker betont wird. 8

Die letzte ,Metamorphose' des Dramas fand in Leipzig und Dresden statt, wohln Schiller Im Frühjahr 1785. auf Einladung Gottfried Körners übersiedelte. Der Dichter fand in diesem Menschen den "lieben Wanderer," der ihn auf seiner "Reise zur Wahrhe1t, zum Ruhme, zur Glückseligkeit so brüderlich und treulich begleiten" sollte." Dieser Bund, der für das ganze Leben Schillers wichtig ist, hat sicher seine Entwicklung zur klassik gefördert. Der ältere körner war Rechtsanwalt, aber außerdem ein Mann, dessen praktischer Sinn und klare Urtellskraft den Genius Schillers genau erkannt hat. Körner hat nicht nur durch philosophische, theologische, und musikalische Interessen einen groBen EinfluB auf Schiller gehabt. Darüber hinaus hat er sich als ein verläBlicher und 
sorgender Freund erwiesen. ${ }^{10}$ Unter Körners EinfluB verschiebt sich also das dramatische ,Schwergewicht. ganz zugunsten Posas und seiner traumhaften Vorstellung von einem neuen Staat. Davon schreibt Schiller im ersten Don Carlos-Brief:

Während der Zelt nämlich, daß Ich es ausarbeitete... hat sich in mir selbst vieles verändert... Was mich zu Anfang vorzüglich in [äiesem Werk] gefesselt hatte, tat diese Wirkung in der Folge schon schwächer und am Ende nur kaum noch. Neue Ideen, die indes bei mir aufkamen, verdrängten die frühern; Carlos selbst war in meiner Gunst gefallen, vielleicht aus keinem andern Grunde, als weil ich ihm in Jahren zu weit vorausgesprungen war, und aus der entgegengesetzten Ursache hatte Marquis Posa seinen platz eingenommen. So kam es denn, da $B$ tch zu dem vierten und fünten Akte in ganz anderes Herz intbrachte. 11

Vor allem widerspiegelt sich der Freundschaftsbund zwischen Schiller und Körner in dem Verhältnis von Don Carlos und Marquis Posa. Der Keim der dichterischen Entwicklung lag in dem persönlichen Erlebnis Schillers. Die Idee der persönlichen Freundschaft stelgerte sich in diesem Drama zur Idee der allgemeinen Menschenliebe.

Don Carlos/Marquis Posa

Die Rede war also davon, .. einen Fürsten aufzustellen, der das höchste mögliche Ideal bürgerlicher Glückseligkeit für sein Zeitalter wirklich machen sollte- nicht diesen Fürsten erst zu diesem Zwecke zu erziehen; denn dieses mußte längst vorhergegangen sein und konnte auch nicht wohl zum Gegenstand eines solchen Kunstwerks gemacht werden; noch weniger thn zu diesem..Werke wirklich Hand anlegen zu lassen, denn wie sehr würde dieses die engen Grenzen eines Trauerspiels überschritten haben?- Die Rede war davon, diesen Fürsten nur zu zelgen, den Gemutszustand in ihm herrschen zu machen, der 
einer solchen Wirkung zum Grunde liegen muß, und thre subjektive Moglichkeit auf einen hohen Grad der wahrscheinlichkeit zu erheben, unbekümert, 12 ob Glück und Zufall sie wirklich machen wollen. 12

Don Carlos ist der Kronprinz des spanischen Weltreiches. Im ersten Auftritt des Dramas scheint er unruhig zu sein. Domingo, der Vertreter der kirchlichen Macht am Hofe Philipps, versucht die geheime Liebe des Prinzen zur Mutter zu erkunden. Carlos zelgt sich aber verschlossen und miBtraulsch dem Priester gegenüber. Der Adlige ist nachdenklich;er zelgt elnen gleichsam "felerlichen Kummer." Wie Hamlet aber, durchschaut auch der Prinz das falsche Splel, d.h. die schmelchelnde Miene Domingos. Carlos we1B, daß Domingo dle Kardinalswürde, also den "purpur" zu gewinnen sucht. Wahrscheinlich möchte der Geistliche eines Tages sogar den päpstlichen Stuhl ersteigen. $D a B$ dieser von einem religiösen Ehrgeiz motiviert wird, 1st klar, aber Carlos berührt es nicht. Er leidet an etwas ganz anderem, an der Leidenschaft für die königin. Da solche Gefühle sich nicht unterarücken lassen, will Carlos alles bekennen. Er kann es aber nicht, denn dieser Priester, der im Auftrag des königs steht, verdient kein menschliches Vertrauen. Das kann nur einem Freund geschenkt werden, dem Marquis Posa. Diesem Menschen kann Carlos alles sagen, was ihn bedrängt, ohne Angst verraten $z u$ werden.

Posa, sein Jugendfreund, lst gerade von einer längeren Re1se nach Europa zurückgekomnen. Carlos enthüllt 
Ihm das Geheimnis seines Herzens: er liebt selne Stiefmutter, die Königin Elisabeth, die thm ursprünglich als Braut zugedacht war. Er hat seine Geliebte an seinen Vater, Könlg Philipp, verloren. Bel dieser ersten Begegnung zwischen Carlos und Posa brechen aus dem prinzen die thn beherrschenden Leidenschaften hemmungslos, in "stürmischem Entzücken," hervor. Selne Freundschaft, und seine Liebe beherrschen Carlos. (Dleser Gefühlsausbruch entspricht Schillers eigener Sturm- und Drangfugend.)

Marguis Posa tritt dem Prinzen von Anfang an beherrscht und abwehrend entgegen. Er lst der vertreter eines unterdrückten Volkes:

Mit offnen Sinnen, mit allen Kräften der Jugend, allem Drange des Genies, aller Wärme des Herzens in das weite Universum geworfen, sieht er den Menschen im großen wie im kleinen handeln, er findet Gelegenhe1t, sein mitgebrachtes Ideal an den wirkenden Kräften dẹr ganzen Gattung zu prüfen. Alles, was or hört, was er sieht, wird mit lebendigem Enthusiasmus von thm verschlungen, alles in Beziehung auf jenes Ideal empfunden, gedacht und verarbeitet. Der Mensch zeigt sich ihm in mehrern Varietäten; in mehrern Himmelsstrichen, Verfassungen, Graden der B1ldung und Stufen des Glückes lernt er ihn kennen. So erzeugt sich in ihm allmählich eine zusammengesetzte und erhabene Vorstellung des Menschen im großen und ganzen, gegen welche jedes einengende kieinere Verhlltnis verschwindet. Aus sich selbst tritt er jetzt heraus, im großen Weltraum dehnt sich seine Seele ins Weite.Merkwürdige Menschen, die sich in seine Bahn werfen, zerstreuen seine Aufmerksamkelt, tellen sich in seine Achtung und Liebe.-An die stelle eines Individuums tritt bel ihm jetzt das ganze Geschlecht; ein vorübergehender jugendlicher Affekt erweitert sich in eine allumfassende unendliche philanthropie. Aus einem müBigen Enthusiasten ist ein tätiger handelnder Mensch geworden.13

Schiller bezelchnet thn im allgemeinsten sinne: "ein 
Abgeordneter der ganzen Menschheit." Carlos 1st genau der Gegenpol selnes Freundes. Der liebebedürftige Königssohn sleht nur die Not seines Herzens. Er wird in dem mehrmals wiederholten Wort "Tränen" symbolisiert: „heibe Tränen/ schwere Tränentropfen/ mit tränendem Gesicht/ Tränengüssen." Posa dagegen ist sparsam in seinen ÄuBerungen. Er lst der Planende, der Berechnende, und kennt nur ein ziel: Carlos zu seinem früheren Idealismus zurückzuführen, denn Carlos ist die letzte Rettung der flandrischen Provinzen. Er glaubte in Carlos den rebellierenden Freiheitskämpfer wiederzufinden. Doch statt eines Tatmenschen findet er einen zur Leidenschaft geneigten Schwärmer, der keineswegs der Befreier der Nlederlande sein könnte: "Vergebung, mein teurer Prinz, wenn lch dies stürmische Entzücken mit Bestürzung nur erwidre. So war es nicht, wie ich Don Philipps Sohn erwartete... Das ist der löwenkühne Jünglich nicht, zu dem eln unterdrücktes Heldenvolk mich sendet-" $(I, 2)$ Carlos verzwelfelt an seinem Vater. Er weiB nicht, ob er thn liebt oder haBt. Elnerseits lst also der prinz bitter, andererselts glaubt er, er müsse in eine versöhnung eingehen.

Carlos versteht sein Schicksal auch nicht: warum müssen zwel völlig unvereinbare Wesen, er und sein Vater, zusammengezwungen werden. "Warum muBt es geschehen? Warum zwel Menschen, die sich ewig meiden, in $E$ inem 
Wunsche schrecklich sich begegnen?" (I,2) Carlos sieht dieses Verhältnis als ein schreckliches Los, dem er nicht entrinnen kann. Überzougt ist er, daB er jetzt einen Freund braucht. Er beklagt sich über seine Lage, einer freundlosen Welt ausgesetzt zu sein. Er sieht sich als "Waisenkind,"einen Menschen, dem keine Llebe geschenkt wird. Er fühlt sich wie eine verwahrloste. Insel,' mitten in elnem kalten, verständnislosen ,Ozean.' Er kann nicht an die Vergangenheit denken. Die Träume der Jugenzeit sind unerfüllbar. Und wie kann er für die etwa übermenschliche Freiheltsidee kämpfen, wenn seine eigene Existenz in Frage gestellt ist. Er kann nur an seine eigenen Probleme denken. Er zeigt nicht nur eine schwärmerische, sondern auch eine selbstsüchtige Natur.

Posa versteht den verzweifelten Zustand des Freundes. Daher zwingt er den Prinzen zu keiner elligen Heldentat. Posa weib, daB Carlos überhaupt keine Rolle in den Niederlanden spielen kann, wenn er in einem so deprimierten Zustand bleibt.

Des Freundes Pflicht wär es gewesen, auf Erstickung dieser Leidenschaft und keineswegs auf ihre Befrledigung zu denken. Posa, der Sachwalter Flanderns, handelt ganz anders. Ihm lst nichts wichtiger, als difesen hoffnungslosen Zustand, in welchem die tätigen Kräfte seines Freundes versinken, auf das schnellsste $\mathrm{zu}$ endigen, sollte es auch ein kleines Wagestück kosten. Solang sein Freund in unbefrledigten wüschen verschmachtet, kann er fremdes Leiden nicht fühlen; solang seine Kräfte von Schwermut niedergedruckt sind, kann er sich zu keinem herolschen Entschlusse erheben. Von dem unglücklichen Carlos hat Flandern nichts zu hoffen, aber vielleicht von dem glücklichen... Was kann [Fos] 
anders tun, als diesen erloschnen Heldengeist an fremden Feuer entzünden und die einzige Leidenschaft nutzen, die in der Seele des Prinzen vorhanden ist? 14

Der Marquis erklärt $s 1 \mathrm{ch}$ aus Freundschaft bereit, Carlos zu einer Unterredung mit der Königin zu verhelfen. Carlos denkt, daB sich seln Freund also verpflichtet fühlt, Ihn zu der Geliebten zu führen. Gäbe es ein weiteres Motiv, so geht es Carlos nichts an. Er ist ein typischer phantast, der nicht die Wahrhe1t, sondern die Erfüllung selner Triebe wünscht.

Posa lst jedoch der für die Idee der völkerfretheit besessene Menschenfreund. "- es sind die Flandrischen provinzen, die an Ihrem Halse weinen, und feierlich um Rettung sie bestürmen. Getan ists um Ihr teures Land, wenn Alba, des Fanatismus rauher Henkersknecht, vor Brüssel rückt mit spanischen Gesetzen." $(I, 2)$ Posa weicht auch nicht davon zurück, die ganze Welt zu bekämpfen. Doch daran wird er scheitern. Es wird sich schlieblich herausstellen, daB er seinen Idealismus zu weit getrieben hat.

Der Charakter des Marquis Posa ist fast durchgängtg für zu idealisch gehalten worden; inwiefern diese Behauptung Grund hat, wird sich dann am besten ergeben, wenn man die elgentümliche Handlungsart dieses Menschen auf ihren wahren Gehalt zuruckgeführt hat. Ich habe es hier, wie sie sehen, mit zwei entgegengesetzten parteien zu tun. Denen, welche ihn aus der Klasse natürlicher Wesen schlechterdings verwiesen haben wollen, müBte also dargetan werden, inwiefern er mit der Menschennatur zusammenhängt, Inwlefern seine Gesinnungen wie seine Handlungen aus gehr menschlichen Trieben. fließen und in Verkettung auBerlicher Umbtände gegründet sind; diejenigen, welche ihn den Namen elnes göttlichen Menschen geben, brauche $1 \mathrm{ch}$ nur auf einige Blößen an ihm aufmerkaamizu machen, die gar menschlich sind. Die 
Gesinnungen, die der Marquis äulert, die philosophie, die ihn leitet, die Lieblingsgefühle, die thn beseelen, so sehr sie sich auch über das tägliche Lebén erheben, können, als bloße Vorstellungen betrachtet, es nicht wohl sein, was ihn mit Recht aus der Klasse natülicher Vesen verbannte. Denn was kann in einom menschlichen Kopf nicht Dasein empfangen, und welche Geburt des Gchirns kann in elnem gluhenden Herzen nicht..zur Leidenschaft reifen? Auch selne Handungen können es nicht sein, die, so selten dies auch geschehen mag, in der Geschichte selbst ihresgleichen gefunden haben; denn die Aufopferung des Marquis für seinen Freund hat wenig oder nichts vor dem Heldentode elnes Curtius, Regulus und anderer voraus. Das Unrichtige und Unmögliche mübe also entweder in dem Widerspruch dieser Gesinnungen mit dem damaligen Zeitalter oder in ihrer Ohnmacht und threm Mangel an Lebendigkeit liegen, zu solchen Handlungen wirklich zu entzünden. Içh kann also die Einwendungen, welche gegen die Natürlichkeit dieses Charakters gemacht werden, nicht anders verstehen, als daB... kein Mensch so wie Marquis Posa gedacht haben konnte, - daB Gedanken dieser Art nicht so leicht, wie hier geschieht, in den willen und in die Tat übergehen,- und daß eine itealische schwärmerei nicht mit solcher Konsequenz realisiert, nicht von solcher Energie im Handeln begleitet zu werden pflege. 15

Im vierten Auftritt erscheint Posa am Hofe der Königin. Es gelingt ihm dies auch in der Abgeschiedenheit der Sommerresidenz von Aranjuez, trotz des strengen Hofzeremoniel1s, das die Königin umglbt. Er erweist sich als der gewandte, vielgereiste Mann, der die Sprache der schmeichelei gut beherrscht. Elisabeth nennt thn einen "Frelen," und "Philosophen;" sie stellt ihn also über den könig: Posa wird als Ausnahme innerhalb der unfreien opanischen Welt gekennzeichnet. Kurze Anspielungen auf die Verhältnisse in spanien schelnen das geheime Einverständnis zwischen der Königin und dem Marquis aufzu- 
zeigen. Diese Anspielungen, auch auf den Prinzen, gehen dann in die Erzählung Posas von dem Schicksal Fernandos und Mathildes über. Dadurch wird der Königin der Lage des Prinzen dargestellt. Sie wird auch innerlich getroffen davon, denn das Schicksal bezieht sich letzhin auf ihre eigene Lage. Sie klagt: „Die Geschichte... muB zu Ende sein." Die Prinzessin Eboli entfernt sich, und Elisabeth "erbricht" die Briefe aus den Niederlanden. Sie wird überrascht, doch ehe es zu einem Gespräch über Carlos kommt, stürzt dieser vor die FüBe der Königin.

Die darauf folgende szene zwischen Carlos und Ellsabeth gewinnt eine dramatische Spannung. Seine Geliebte' erhebt die Worte "Königin" und "Mutter" wie einen Schild gegen den Ansturn des in seiner Leidenschaft maBlos werdenden Carlos. Gerade indem sie sich hinter ihre "Pflicht" zurückzieht, weist sie auf ihr verhältnis zum König. Carlos entdeckt sich der königin, aber sie scheint seinen Erklärungen wenig geneigt zu sein. Trotz seiner verwegenen Manieren versteht sie diesen jungen Menschen. Um die Leidenschaft des Prinzen zu sublimieren, setzt sie inre Erzlehungsaufgabe ein: er sollte an das Königtum denken, an seine größere Aufgabe als Thronfolger des gewaltigen Reiches. "Blisabeth war Ihre erst Liebe, Ihre zweite sel Spanien." Dieses neue "Amt" der Liebe wird also als Befrledigung der Selbstsucht, als GenuB der Macht gesehen. 
Das Erziehungswerk Posas und der Königin trägt Früchte. Carlos ist entschlossen, Flandern zu retten, und schlieBt einen Freundschaftsbund mit Posa. "In des Worts verwegenster Bedeutung" widmen sich beide der vorbereltung eines neuen zeltalters. Sie wissen aber, daß Carlos die entscheidendste Rolle spielen muB. Nur dieser verfügt über die Nittel, womit man an die Macht treten kann. Carlos ist Erbe des königlichen Relches, die letzte Hoffnung einer leidenden Menschheit.

Der neunte Auftritt gilt dem Preis der erzieherischen Männerfreundschaft, die sich unter den Idealen der Menschlichkeit verbirgt. In dem Dialog der Freunde betont Schiller seine hohe Auffassung von der Preundschaft zwischen Männern. "Die Freundschaft ist wahr und kühn." Der Dichter sieht darin eine bereichernde, schöpferische Macht, sie auf alles Menschliche wirkt. In dem "Gemälde" von dem absoluten Monarchen und Diktator, das Posa in den kräftigsten Farben schildert, wird nicht nur die verantwortung erwähnt, sondern auch die Gefahr eines unbestrittenen Machthabers. "Die Menschheit, - noch heut ein groBes Wort...- verkauft sich selbst und kriecht um thren Götzen." $(I, 9)$ Der einzelne Mensch kann eine Gefahr für dle ganze Menschhelt werden. Nur der freie Mensch, der von Leidenschaften sowohl wie von Besitzgler freie Mensch, kann gegen die tyrannische Machtfülle kämpfen. In dem schlußwort Carlos', hallt 
Schillers Hymnus an die Freundschaft wieder. Es erinnert an den Bund mit Körner, wodurch der Dichter die Begeisterung für die Ideale der Humanität und einer kommenden politischen ordnung erfahren hatte.

Von Gefühlen der Freundschaft und der Liebe getrieben, wagt sich Carlos in den Bereich des Vaters. Die entscheidende Aussprache findet im königlichen Palast zu Madrid statt. Carlos fordert, daB er sich Auge in Auge mit seinem Vater, ohne die Gegenwart des Herzogs von Alba, unterhalten kann. Alba lst der feindliche Gegenspieler. Er muB von der Unterredung entfernt werden. Die Worte gegen den Herzog "In seines Nichts durchbohrendem Gefühle" sind allerdings beleldigend und verächtlich. Auch wenn wir das "Nichts" bloB als Hinweis verstehen wollen, daB Alba bel dem Gespräch nichts zu tun habe, ist der Ton des prinzen grausam. Carlos unternime in dieser "längst erbetenen großen stunde" den letzten Versuch elner versöhnung mit seinem vater und bittet ihn um das Kommando über das Heer, das nach Flandern geschickt werden soll. Der König beharrt aber bei seiner Meinung, daB dieses Amt einen Mann wie Alba erfordere, also keinen heiBblütigen, unerfahrenen Jüngling. Wenn Carlos $(I I, 2)$ den König durch einen leidenschaftlichen Ansturm des Herzens zu gewinnen sucht, so ist der Zweifel Philipps an dessen Ehrlichkeit nicht unberechtigt. Philipp sagt ihm, "[sein Herz weiB nichts von diesen Künsten." Die "Tränen" des Sohnes werden 
jetzt zu einem unwürdigen Anblick, und bekräftigen keine verantwortliche Haltung dem Staat gegenüber. Deswegen muß der König seinem Sohn die Bitte abschlagen, denn der Jüngling wäre doch kein fähiger Nachfolger.

Carlos bestätigt selbst, daB Philipps zurückhaltung berechtigt 1st. Carlos behauptet aber auch seine brennende Begeisterung: "[vater] geben sie mir zu zerstören." Er sei drelundzwanzig Jahre alt, und habe nichts für die "Unsterblichkeit" getan. Carlos will sich als tatkräftiger Mensch erweisen. Er braucht nur eine Chance, um die Weltgeschichte zu ändern. Der könig hat aber Grund dafür, nicht nur "seine weiche Seele," sondern seine "Herrschbegierde" zu fürchten. Philipp geht so weit, Carlos strebe nur danach, das beste Kriegsheer spaniens in die Hände zu bekommen, um zu dem Mörder des Vaters zu werden. Es kommt also darauf an, was Carlos eigentlich meinte $(I, 2)$. Waren die "schauerlichen Träume," die "gräBlichen Entwürfen" auf den Mord des Königs gezielt? Es ist unklar, ob Carlos ein vernünftiger, rationaler Mensch ist, oder ein Schwärmer. Man weiB nicht, ob Carlos einer gewissenhaften oder einer gewissenlosen Tat fähig ist. Doch scheint der König von einem staatpolitischen, aber auch von einem menschlichen Standpunkt dazu berechtigt, wenn er seinen Sohn nicht an der spitze des Heeres nach Flandern schickt. Die Unreife des Infanten bezeugt sich offensichtlich in diesem Gespräch. Sch1ller schreibt über seine Charakteri- 
oierung des jungen Prinzen in den Briefen über Don Carlos:

Sie begreifen nun auch, warum der Prinz so und nicht anders gezeichnet worden; warum ich es zugelassen habe, daß die edle Schönheit dieses Charakters durch so viel Heftigkeit, so viel unstete Hitze, wie ein klares Wasser durch Wallungen, getrübt wird. Ein welches, wohlwollendes Herz, Enthusiasmus für das Große und Schöne, Delikatesse, Mut, Standhaftigkeit, uneigennützlge Großmut soilte er besitzen, schone und helle Blicke des Geistes sollte er zeigen, aber welse sollte er nicht sein. Der künftige große Mann solite in ihm schlummern, aber ein feuriges Blut sollte thm jetzt noch nicht erlauben, es wirkilch zu sein. Alles, was den trefflichen Regenten macht, alles, was die Erwartungen seines Freundes und die Hoffnungen einer auf ihn harrenden Welt rechtfertigen kann, alles, was sich vereinigen muB, sein vorgesetztes Ideai von einem künftigen Staat auszuführen, sollte sich in diesem Charakter beisammen finden: aber entwickelt sollte er noch nicht sein, noch nicht von Leidenschaft geschieden, noch nicht zu reinem Golde geläutert. Darauf kam es ja elgentlich erst an, thn dieser vollkommenheit näher zu bringen, die thm jetzt noch mangelt; ein mehr vollendeter Charakter des Prinzen hätte mich des ganzen Stücks überhoben. 16

Bedeutend ist es auch, daB der König von dieser szene mit dem allzu gefühlvollen Sohn nicht unberührt geblieben ist. Das "nicht ohne Rührung" wiederholte " $O$, mein Sohn..." verrät die Stimmung seines Herzens. Carlos ist nicht nur der Sohn eines Monarchen, sondern auch einer väterlichen Figur. Der König bleibt aber gleichsam ,verschlelert,' bis dahin, wenn er den Marquis später trifft. Posa ist wiederum auch der Erzieher, der eine bedeutende Wirkung auf den König haben kann. Elne solche Rolle kann aber nicht dem Prinzen zugeschrieben werden. Er ist keine erzieherische, sondern eine leicht beeinfluBbare Gestalt. Carlos lot viellelcht Erbe des königlichen Reiches. Er 1st aber nicht Imstande, einen Gegner 
allein zu bekämpfen. Ohne den Freund geht Carlos zugrunde. Der Prinz kann nur die Leistungen Posas fortsetzen. Der Marquis lat eine ursprüngliche Kraft, während Carlos inn nur nachahmt.

Posa fühlt auch die GröBe seiner Stunde, die ihn zur Audienz bel dem König beruft. Er weiB, was es gilt: "Und wärs auch eine Feuerflocke Wahrheit nur, in des Despoten seele kühn geworfen-" (III,9). Was dem Marquis als Zufall erscheint, d.h. die Berufung vor dem könig, w111 Posa also vorsichtig nutzen. Im fünften Don CarlosBrief weist Schiller auch darauf: "Noch ist es nicht ein klarer zusammenhängender Plan, was er sich denkt; bloB flüchtig aufsteigender Einfall ist es, ob hier vielleicht gegegenlich etwas sein möchte? Er soll vor denjenigen treten, der das Schicksal so vieler Millionen in der Hand hat... Mehr denkt er sich nicht dabel, als einen zufälligen Umstand auf die beste Art, die er kennt, zu benutzen. In dieser stimmung erwartet er den könig."

*. In der nun folgenden Audienzszene (III,10) ist Posa der große Rhetoriker, der die politischen Ideale der Aufklärung offen verkündet. Im stolzen, selbstbewuBten Auftreten, sagt er dem König offen Ins Gesicht, daB es thm unmöglich sel, "Fürstendiener" $z$ u werden. Dazu greift Posa das Herrschaftssystem des Absolutismus schonungslos an. Er macht einen Angriff, der den könig in seiner menschlichen Eipsankeit trifft, ganz unmittelbar an der vielleicht 
wundesten Stelle des Herzens: „Bel Gott, er greift in meine seele."

Wenn man Posas Ideen analysiert, so zielen sie auf eine konstitutionelle Monarahie. Seine Gedanken sind aber zum Te11 widerepruchsvoll, doch noch immer bezelchnend für die innere Fassung eines Idealisten. Er meint zuerst, daß das Jahrhundert für seine Ideale noch nicht reif sei. "[er lebe] ein Bürger, derer, welche kommen werden." Dann sagt er aber, und darin zeigt sich der widerpsruch zu einem Mordplan, daß mit "elnem Federzug" des Königs die Erde "neu erschaffen" werde. Wenn der könig also den frelen und gleichberechtigten Bürger geschaffen habe, sei es sogar die Pflicht Philipps "die Welt zu unterwerfen," um sie an diesem glücklichen königreich teilhaben zu lassen. Posa, Verkünder der Menschheit, wird zu einem ,Rebell,' der um seines Ideals willen, die Welt erobern, und die Menschheit zu seinem idealen Glück zwingen will. Posa ist überzeugt, der könig könne den Idealstaat verwirklichen. Wenigstens im spanischen Reich sollte sich eine Höhe des Menschenglückes erreichen lassen. Dann gälte es, die ganze Welt diesem Ideal zu unterwerfen, ob sie es mag oder nicht.

Posas Ideologie der Freiheit beruht auf einem optimistischen Menschheitsglauben. "Der Mensch 1st mehr als Sie von ihm gehalten." Philipp glaubt, daß der Mensch Freihelt nicht ertragen kann; dagegen ist Posa der festen 
Meinung, der Mensch kann Freiheit nicht nur vertragen, sondern sie lat seine wahre Bestimmung. ${ }^{18}$ Erst durch sie wird der Mensch überhaupt zum "wahren Menschen," während dle Unterdrückung der Freiheit seine Seele nur unterdrückt. Aber der Marquis versteht auch, daB Philipp nlchts anderes als eine schlechte Menschheitsauffassung haben kann: die Menschenkenntnis des könlgs beruht also auf der Kenntnis jener "verächtlichen Kreaturen," die seinen Thron umgeben. Posa weist daraufhin, daB diese Menschen den König dazu gezwungen haben, die Menschheit selber herabzustellen. Darauf erwidert der König: „Etwas Wahres find" Ich in diesen Worten." Aber was Posa nicht ausspricht, ist genau so wichtig: wenn die Menschheit im Jahrhundert Philipps noch nicht reif zur Freiheit ist, dann trägt der Despotiamus selbst die Schuld daran. Wenn also der Despotismus sich gerechfertigt glauben kann, daß der Mensch nichts als knecht ist, dann wird dem Menschen das höchste Ideal vorenthalten: die Freiheit. ${ }^{19}$ Daher fordert Posa nachdrücklich, daB er Gedankenfreiheit brauche. Er unterstützt diese Forderung: keine Gewaltmaßregel werde imstande sein, "der Christenheit gezeitigte Verwandlung, den allgemeinen Frühling aufzuhalten, der die Gestalt der Welt verjüngt." Posa fügt hinzu: "Sie wollen allein in ganz Europa sich dem Rade des Weltverhängnisses, das unaufhaltsam in vollem Laufe rollt, entgegenwerfen? mit Menschenarmen in seine Speichen fallen? 
Sie werden nicht." Posa glaubt also, daß die Weltgeschichte eine Geschichte der Freiheit ist.

Der König, betroffen von den Worten des Marquis, weiB trotzdem nichts anderes zu erwidern als die Warnung vor der Inquisition. SchlieBlich zeigt sich Posa in diesem Auftritt als Schmeichler, wenn er den König den „Glücklichsten" nennt, obwohl Posa die Spannungen zwischen Vater, Sohn und Mutter genau kennt. Der könig sieht aber in Posa die geeignete Persönlichkeit, die das private Familtenleben, die Treue der Königin, erforschen soll. Obgleich Posa für Philipp nur ein auBerordentlicher Schwärmer 1st, weiB der König die ungewöhnliche Art dieses Idealisten zu schätzen. Er nimmt thn also in seinen Dienst, und macht thn zum Vertrauten seiner persönlichen Nöte. Der Marquis soll künftig eine wichtige Rolle am Hof spielen. Um seine eigenen pläne zu fördern, d.h. die Befreiung der Niederlande durchzuführen, nützt er diese neue Funktion. Carlos soll helmlich nach Brüssel und dort eine Rebellion anstiften: Carlos muB die spanische Krone zwingen, milder mit den Provinzen zu verfahren. Der Gang der Handlung wird also von fetzt ab durch Marquis Posa bestimmt. Durch seine unbesonnenen Aktionen treibt der Kämpfer sich und sein Werk in den Untergang.

Schiller sucht das ungestüme Verhalten dieses jungen Mannes im elften Don Carlos-Brief zu erklären. Darin befasst aich Schiller mit der psyche des fanatischen 
Idealisten, der die Wirklichkeit zu wenig sieht. Aus Herrschsucht sieht Posa nicht die natürlichen Regungen des Menschenherzens. Obgleich er willkürlich mit den Menschen umgeht, berücksichtigt er sie in seinen weltweiten Planungen und "allgemeinen Abstraktionen" nicht genügend:

Geräuschlos, ohne Gehülfen, in stiller Größe zu wirken, ist des Marquis Schwármerei. Still, wie die Vorsicht für einen Schlafenden.sorgt, will er seines Freundes Schicksal auflösen. Er [Posa] will inn [Carlog] retten, wie ein Gott- und eben dadurch richtet er inn zu Grunde. DaB er zu sehr nach seinem Ideal von Tugend in die Höhe und $z u$ wenig auf seinen Freund herunterblicke, wurde beider Verderben. Carlos verunglückte, wetl sein Freund sich nicht begnügte, ihn auf eine gemeine Art zu erlösen." 20

Carlos muB aber letzten Endes um der schwärmerischen Ideale Posas willen, aus allen natürlichen Bindungen herausgelöst und gereinigt werden. Ein Zustand geistiger Objektivität ist das ziel der ideellen Erziehung, die Marquis posa an seinem zögling vornimmt.

Die Königin kann zu der seelischen Entlarvung des Idealisten auch beitragen. Im Raum des Dramas verkörpert sie die reine Liebe, in der sich Wahrheit und Schönheit begegnen. ${ }^{21}$ Die Königin lehnt die Idealisterung Posas ab. Sie verweist auf ihre Weiblichkeit und zieht sich zurück auf die Autorität ihres Herzens. Sie versteht Posa aber und spürt die psychologischen Bedingungen, deren sich der Idealist nicht bewuBt ist. Die glaubt, daB auch hinter dem Spiel des opfers ein raffinierter egozentrischer 
Wille zur Macbt steht. "Sie haben nur um Bewunderung gebuhlt." Die Königin macht Posas selbstsüchtige Beweggründe zur Tat sichtbar. Angesichts dieser Entlarvung ist es vielleicht der bedeutendste Augenblick im Drama, wenn der idealistische Posa von dem schönen Leben sprechen kann. Die groBe Idee, also das Traumbild des neuen Staates, fordert aber, daB $\underline{\text { ihr }}$ dieses schön Leben geopfert werden müBte.

Der letzte Auftritt betont die tragische Ironie des Dramas. In dem Augenblick also, in dem der Erziehungsplan Posas sich an Prinzen vollendet, wird dieser der Inquisition übergeben. Er will auf den Besitz der königin verzichten: „Es gibt ein höher, wünschenswerter Gut, als dich besitzen_- Auch ist er jetzt der über die menschliche Natur Erhabene, und dafür bewundert ihn Elisabeth. Sie weint aber, da sie im Sinne Posas und seines Idealismus noch zu natürlich, also nicht erhaben genug ist. Sie kann einfach nicht anders.

Die letzte Station des Erziehungsweges für den Prinzen 1st der Tod Posas. Es ist ein Opfertod für die ideale Haltung und für den politischen Auftrag des Don Carlos: "... er stirbt dafür, warum mehrere groBe Menschen für eine Wahrhelt starben, die sie von vielen befolgt und beherzigt haben wollten: um durch seln Beispiel darzutun, wie sehr sle es wert sel, dab man alles für sle leide."22 
Am Ende seiner Entwicklung steht aber Carlos auBerhalb der natürlichen Wallungen, ganz ergeben den Idealen Posas. Carlos ist also über die Natur erhaben, wie es sein Freund war: „Ausgestorben 1st in meinem Busen die Natur... Ich eile, mein bedrängtes Volk zu retten von Tyrannenhand... Jetzt trotz ich jedem Schicksal der Sterblichkeit." Der vollendete Idealist ist wiederum zu einem naturlosen $\mathrm{Zu}$ stand hinaufgestiegen. 23

M1t der Verhaftung des Prinzen lst das Abenteuer des politischen Idealisten Marquis Posa gescheitert. Unbeantwortet bleibt aber die Frage, ob die "rebellierenden" Gestalten des Dramas überhaupt Rebellen sind. Zunächst einmal hätte sich eln derartiger Mensch dem Gegner nicht unterworfen. Einer seiner Charakterzüge ist also eln trotzendes Temperament. Unter keinen Unständen würde der Rebell zugeben, daB er sich der Gesellschaftsordnung anpassen sollte. Statt dessen 1st der Rebell nicht nur geneigt, diese ordnung zu beobachten; sondern er greift sie kräftig an. Der Marquis lst ja ein handelnder Mensch, der ein untergehendes Volk zu retten sucht. Es ist das Traumbild eines Idealstaates, das ihn dazu treibt, sich letzten Endes aufzuopfern. Das ist aber schon ein Widerspruch. Indem der Opfertod nur als selbstmord anzusehen ist, besteht die Frage: stirbt ein Rebel1 freiwillig? Unbedingt nicht, denn der Tod schliebt selbstverständlich das Leben aus, und 
unerblttlich kämpft der Rebell für das Leben. Er rebelliert, um seinen Lebensplan zu erfüllen; er würde den eigenen Tod auf keinen Fall wählen. Obgleich der Marquis Carlos fast zur "groBen Tat" treibt, entspricht seine Opferbereitschaft keiner rebellierenden Gesinnung.

Zu gletcher Zeit scheint es auch nicht, daß Carlos ein konsequenter Rebell ist. Es stimmt, daB sich der junge Prinz in einen aufgeregten Menschen verwandeln läBt, d.h. in einen Menschen, der von der "großen Idee" beseelt ist. Es gelingt dem Prinzen aber nicht, seinen feurigen Plan zu verwirklichen. Am Rande des Rebelllerens wird er gefangen genommen. Er versagt, ehe er sich als Held beweisen kann. Wenn man Carlos also bezeichnen müBte, ist er schlieB11ch nur der Schwärmer: er träumt, aber seine Träume werden zu nichts: "Ein weiches, wohlwollendes Herz, Enthusiasmus für das Große und Schöne, Delikatesse, Mut, Standhaftigkeit, uneigennützige GroBmut sollte er besitzen, schöne und helle Blicke des Gelstes sollte er zeigen, aber welse 1st er nicht." 
FÜNFTES KAPITEL

\section{ZUSAMMENFASSUNG}

Karl Moor, Ferdinand, Don Carlos und Marquis Posa stellen einen gemeinsamen Charaktertyp dar. Alle befinden sich in einem egolstischen Kampf um ein großes ziel; alle wollen dieses $\mathrm{Zlel}$ aber auf thre elgene Welse verwirklichen, ohne Rücksicht auf die telt. Daher müssen sie am Ende scheitern. Sie sind trotzdem moralische junge Männer, die das Unmoralische in der Welt gesehen haben, besonders im Bereich der Staatsgewalt. Naiv sind aber ihre rebellischen Pläne: obgleich diese Gestalten sich letzten Endes in einen geheilten Zustand verwandeln, ist es zu spät, um das groBe Traumbild verwirklichen $z u$ können. Ferdinand verllebt sich in Luise und will sie heiraten. Er kümmert sich nicht um den Klassenunterschied; er legt mehr Wert auf das glückliche Leben mit seiner Geliebten. Des verderbten Hoflebens 1st sich Ferdinand aber auch bewuBt. Doch am Ende wird er von den unmoralischen Menschen am Hof gleichfalls betrogen. Man hat ihn überzeugt, Luise sei ihm untreu geworden. Ferdinand ist ein Egoist, der eine egoistische Idee verfolgt: wenn er Luise nicht für sich selbst haben kann, soll niemand sie besitzen. Er gibt ihr Gift. Den Betrug erfährt Ferdinand zu spät. Er hätte doch eln glückltches Leben führen können, 
hätte er an dle Treue selner Geliebten geglaubt. Sein ,geheliter Zustand' kann aber das gemeinsame Glück nicht retten. Tragisch ist es, daB solche naiven Menschen sterben müssen, ohne eine bedeutendere Wirkung auf die Welt zu haben.

Don Carlos verliebt sich in Ellsabeth. Seln Vater macht sie zu seiner Braut, denn der vater ist der mächtigere Gegner Im Raum der Herrschaftspolitik. Seinem Charakter entsprechend, protestiert Don Carlos gegen das herrschende Verhalten seines vaters und schlieBlich auch gegen die absolute Monarchie. Der Prinz ist aber kein fählger Kämpfer. Im letzten Augenblick macht er sich die Befrelung der Fiederlande zu seinem neu erworbenen Ideal. Wie immer gelangt aber auch dieser morallsche und natve Mensch zu spät zu seiner Umkehr. Er wird als Staatsgefangener verhaftet.

Marquis Posa vertritt eine idealistischere, wenn auch noch rebellische Lebensphilosophie. Er sagt, er sei kein „Fürstendiener." Posa sieht -sich nicht als Werkzeug eines politischen systems. Posa glaubt, er werde den König positiv beelnflußen können, d.h. dem Monarchen elnreden, Philipp könne den Idealstaat verwirklichen. Im Grunde will Posa die Menschlichkelt auf Kosten des Staates, dagegen Phllipp den staat auf Kosten der Menschlichkeit. Letzten Endes muB sich Posa seinem Traumbild opfern. Er legt alle selne Hoffnungen auf den Prinzen, daB er seine der Mensch- 
heit dienenden Pläne in die grobe Tat umsetzen werde. Die Verhaftung des Prinzen bedeutet aber nicht, daB Posa umsonst gehandelt hat. Elne Verbesserung der gesellschaftlichen ordnung entstammt nicht unbedingt einer naiven Vorstellung der Welt. Das Rebellische an dem Menschen ist oft ein negativer EinfluB. Bei dem Marquis wird aber die rebellische Haltung durch den opfertod gemildert.

Kar1 Moor rebelliert gegen seine Gesellschaft. Er wird Räuber, um gegen die Ungerechtigkeiten seines Zeitalters anzukämpfen. Er kann aber die Gesellschaft, die er haßt, nicht ändern. Obgleich ein Räuber, bleibt Moor idealistisch. Als er endlich die Wahrheit des brüderlichen Betrugs sieht, weiB er was er tun muB: sich gefangen geben. Auf diese Weise geht der naive Held zugrunde. Seine Wirkung auf die Welt 1st nur gering. Ihn anders $z u$ verstehen, würde elne verherrlichung seines Irrenden Lebens sein.

Wenn aber nicht mit großem Erfolg, rebellieren alle diese Gestalten Sch1llers (Karl Moor, Ferdinand, Don Carlos, Marquis) gegen die Weltordnung. Sie gehen zugrunde, indem sie sich dieser mächtigeren ordnung nicht anpassen können. Sle entsprechen also nicht dem Ideal Goethes, indem der Begriff des Selbsthelfers erwähnt wird. 
mir eingewurzelt hatten und sich nach und nach zu poetischen Gestalten ausbilden wollten. Es war Götz von Berlichingen und Faust. Die Lebensbeschreibung des ersten hatte mich im Innersten ergriffen. Die Gestalt eines rohen, wohlmeinenden selbsthelfers in wilder anarchischer zeit erregt meinen tiefsten Ante11. 1

Die "Rebellen" Schillers versuchen thre Ideale durchzusetzen; sie versagen aber am Ende. Sie scheinen dafür ungeeignet, eine lebenswichtige Rolle zu spielen. Das 1st aber nicht das Tragische in diesen sturm- und Drangdramen. Das, was diese versagenden Gestalten schlieBlich kennzeichnet, hat nichts mit der Moral zu tun. Franz, eine durchaus entartete Gestalt, 1st dennoch ein viel konsequenterer Charakter als Karl Moor. Es liegt daran, daB der Erstere von Anfang an ein grotesker Mensch ist, während der Letztere ganz anders wirkt. Karl Moor 1st nicht konsequent in selner Rolle. Er fängt an, die Gesellschaft zu kritisieren, dann versöhnt er sich mit der Umwelt. Kurz danach lst er aber der "Unglückliche," der Betrogene, und rebelliert gegen die gleichen Umweltskräfte, die er früher unterstützt hatte. Was Karl betrifft, 1st die Moral nicht das Grundproblem. viel wichtiger ist eine Lösung seiner wankenden Natur. Wenn man den Grund für seine einmal rebellierende, elnmal nicht rebellierende Haltung entdeckt, werden auch Ferdinand, Don Carlos und Marquis Posa verständ $11 \mathrm{ch}$.

Moor ist unzufrieden mit dem "Kastraten-Jahrhundert," Inden nichts Wertvolles gelelstet wird. Er wäre dazu fähig, 
sein Jahrhundert zu retten. Nachdem er von seinem Vater "verworfen" wird, schließt er sich der Räuberbande an. Er rebelliert also gegen das Gesellschaftssystem, gegen die Welt selber. Allmählich wird es thm aber klar, daB das Räuberleben keine wirkliche zukunft für ihn bletet. Er stellt sich der Justiz, d.h. Schiller glaubt, dieser Held müBte sich aufgeben. Schlllers Auffassung elnes Rebellen hat sich also geändert. Der Dichter weist auf dieses Problem hin in einem späteren Werk. Im Verbrecher aus verlorener Ehre wird die tragische Existenz des rebellierenden Menschen behandelt. Der Held dieser Erzählung heiBt Christian Wolf. Er fühlt sich auch zum Verbrechertum getrieben. Am Ende ist er auch enttäuscht, des Räuberlebens müde:

Ein Jahr schon hatte er das traurige Handwerk getrieben, als es anfinge, ihm unerträglich zu werden. Die Rotte, an deren spitze er sich gestelit hatte, erfüllte seine glänzenden Erwartungen nicht. Eine verführerische Außenseite hatte ihn damals im Taumel des Weines geblendet; jetzt wurde er mit Schrecken gewahr, wie abscheulich er hintergangen worden. Hunger und Mangel traten an die stelle des Überflusses, womit man ihn eingeweigt hatte; sehr oft mußte er sein Leben an eine Mahizeit wagen, die kaum hinrelchte, ihn vor dem Verhungern zu schutzen. Das Schattenbild jener brüderlichen Eințracht verschwand; Neid, Argwohn und Eifersucht wüteten im Innern dieser verworfenen Bande. Die Gerechtigkeit hatte demjenigen, der ihn lebendig ausliefern würde, Belohnung und, wenn es ein Mitschuldiger wäre, noch eine feierliçhe Begnadigung zugesagt- eine mạchtige Versuchung für den Auswurf der Erdel Der Unglückliche kannte seine Gefahr. Die Redlichkelt derjenigen, die Menschen und Gott verrieten, war ein schlechtes Unterpfand seines Lebens. Sein Schlaf war von jetzt an dahin, ewige Todesangst zerfraB setne Ruhe, das gräBliche Gespenst des Argwohns rasselte hinter ihm, 
wo er hinfloh, peinigte ihn, wenn er wachte, bettete sich neben ihm, wenn er schlafen ging, und schreckte thn in entsetzlichen Träumen. 2

Darauf wird er von dem Schuldgefühl verfolgt. Er wünschte, er habe sein Leben nicht verdorben. Die Ursache seines Unglücks wird Immer deutlicher. Er kennt schl1eß11ch nur einen Feind, sich selbst: or wird die Ursache des eigenen MiBgeschicks.

Das verstummte Gewissen gewann zugleich seine Sprache wieder, und die schlafende Natter der Reue wachte bei diesem allgemeinen Sturm seines Busens auf. Sein ganzer Haß wandte sich jetzt von der Menschheit und kehrte seine schreckliche Schneide gegen ihn selber. Er vergab jetzt der ganzen Natyr und fand niemand, als sich allein zu verfluchen.

Wie Karl Moor, wird Christian auch davon überzeugt, daB das Gesetz behalten werden muB, denn ohne die Gesetzlichkeit gehe das ganze Gesellschaftssystem zugrunde. Diese Wahrheit lernen alle "Rebellen" Schillers. Ohne weiteres könnte man also schlieken, daB schiller einfach die Weltordnung unterstützt, $d a B$ er sich gegen eine anarchistische Lebensauffassung stellt. Wahrscheinlich stimmt das, aber das ist nicht der einzige Grund für die Methode des Dichters. Vor allem wollte Schiller auf den Leser wirken. In der Vorrede zu dem Verbrecher aus verlorener Ehre schreibt er über das Verhältnis zwischen dem Dichter und dem Leser, und zwar zwischen dem Leser und dem Held: "Entweder der Leser muB warm werden wie der Held, oder der Held wie der Leser erkalten. ${ }^{4}$ Schiller wollte in das Herz des Lesers dringen, denn nur diese Methode würde das endgültige Werk 
wertvoll machen. Durch das rebellierende, nicht rebellierende Temperament des Helden steigt die Wirkung auf das Publikum. Staiger weist darauf hin in seiner Analyse der Schillerschen Erzählung:

Schiller will rühren, setzt sich über den vorgezeichneten Stil hinweg und gönnt seinem Helden Anstand und Adel. Im Zug der Katastrophe sodann ist ohnehin kein Halten mehr. Mit einer Kunst, die sich um keine wissenschaft von der Seele - es sel denn die des Lesers - kümmert, die rücksichtslose Regle der Affekte Mitleid, Hoffnung, Furcht, Erbarmen 1st, werden.wir dem Ende entgegengefúhrt, dem letzten, erschütternden, stille gebietenden Satz: "Ich bin der Sonnenwirt." 5

Das Schicksal eines Sonnenwirts erinnert uns an die sturm und Drang "Rebellen" des Dichters. 
Zweites Kapitel: Die Räuber (Karl Moor)

1 Benno von Wiose, Schiller, Einführung in Leben und Werk (stuttgart, 1966), S. 14 .

2 wiese, s. 8.

3 otto Mann, Geschichte des deutschen Dramas (Stuttgart, 1960), S. 246 .

4 Friedrich Schiller, Die Räuber: Vorrede (Frankfurt am Main, 1966), S. 8.

5 Friedrich Schiller, Schillers Werke (Weimar, 1956), 23. Band, S. 21.

6

Mann, S. 246.

7 Gerhard Fricke, Der religiöse Sinn der Klassik Schillers (Darmstadt, 1968), S. 80.

8 Fricke, S. 81.

9 Mann, S. 247.

10 Hermann August Korff, Geist der Goethezeit (Leipzig, 1964), 1. Te11, S. 227 .

11 Korff, S. 227.

12 Korff, S. 227.

13 Mann, S. 247.

14 Fricke, s. 164.

15 Mann, S. 252.

16 Emil Staiger, Friedrich Schiller (Zürich, 1967), S. 50.

17 staiger, S. 50 .

18 Mann, S. 253. 
Drittes Kapitel: Kabale und Liebe (Ferdinand)

1 Benno von Wiese, Schiller, Einführung in Leben und Werk (stuttgart, 1966 ), s. 24 .

2 otto Mann, Geschichte des deutschen Dramas (Stuttgart, 1960), S. 258 .

3

Gerhard Storz, Der Dichter Friedrich Schiller (Stuttgart, 1963), S. 103 .

4 Em1l staiger, Frledrich Schiller (Zürich, 1967), s. 265.

5

Karl Ruppel, hg, Reclams Schauspielführer (stuttgart, 1968), S. 292.

6

Mann, S. 258.

7 storz, s. 99.

Viertes Kapitel: Don Carlog (Don Carlos/ Marquis Posa)

1 Reinhard Buchwald, Schiller (Wiesbaden, 1953), s. 6.

2 Friedrich Schiller, Briefe über Don Carlos (Frankfurt am Main, 1966), S. 21-22.

3 Friedrich Schiller, S. 35.

4 Benno von Wiese, Schiller, Einführung in Leben und Werk (Stuttgart, 1966), S. 35 .

5 Rudolf Ibel, Schiller (Frankfurt am Main, 1970), s. 7.

6 Friedrich Schiller, Schillers Werke (Weimar, 1956), 23. Band, S. 143-144.

7 Schillers Werke, S. 155.

8 Ibel, s. 7.

9 Wiese, S. 33.

10 wiese, S. 34 .

11 Friedrich schiller, Briefe über Don Carlos, s. 21. 
12 Friedrich Schiller, S. 46.

13 Friedrich Schiller, S. 28.

14 Friedrich Schiller, s. 31-32.

15 Friedrlch Schiller, S. 22-23.

16 Friedrich Schiller, s. 47-48.

17 Friedrich Schiller, s. 37.

18 Hermann August Korff, Geist der Goethezeit (Leipzig, 1964) 1. Tei1, S. 212.

19 Korff, S. 212 .

20 Friedrich schiller, s. 52.

21 Ibel, 3. 39.

22 Friedrteh schillex, s. 55.

23 Ibel, S. 56.

Füntes Kapitel: Zusammenfassung

1 Johann Wolfgang von Goethe, Dichtung und Wahrheit (Hamburg, 1967), S. 413.

2 Friedrich Schiller, Der Verbrecher aus verlorener Ehre (Frankfurt am Main, 1966), S. 325-326.

3 Friedrich schiller, S. 326.

4 Friedrich Schiller, S. 311.

5 Em1l Sta1ger, Einführung in die Erzählung (Frankfurt am Main, 1966), S. 516. 
Clauss, Walter. Deutsche Literatur. Zürich, 1945.

Ermatinger, Emil. Deutsche Dichter, 1750-1900. Frankfurt am Main, $196 \overline{1 .}$

Fricke, Gerhard. Der religlöse sinn der Klassik Schillera. Darmstadt, 1968.

Garland, Henry Burnard. Sturm und Drang. London, 1952.

Goethe, Johann Wolfgang von. Dichtung und Wahrheit. Hamburg, 1967.

Koopman, Helnut. Friedrich Schiller, 1. Band. Stuttgart, 1966.

Korff, Hermann August. Gelst der Goetheze1t, 1. Te1l. Leipzig, 1964.

Lecke, Bodo. hg. Dichter über ihre Dichtungen, 1. Band. München, $19 \overline{69}$.

Mann, Otto. Geschichte des deutschen Dramas. Stuttgart, 1960.

Newald, Richard. Geschichte der deutschen Literatur, i. Teil. München, 1967.

Pascal, Roy. The German Sturm und Drang. Manchester, 1969 .

Ruppel Karl. hg. Reclams Schauspielführer. Stuttgart, 1968.

Schillemeit, Jost. hg. Deutsche Dramen von Gryphius bis Brecht. Frankfurt am Main, 1966.

Schiller, Friedrich. Schillers Werke, Frankfurt an Main, 1966.

Stahl, Ernst Ludwig. Friedrich Schiller's Drama. Oxford, 1961.

Staiger, Emil. Einführung in die Erzählung. Frankfurt am Main, 1966.

Staiger. Friedrich Sch1lier. Zürich, 1967.

Storz, Gerhard. Der Dlchter Friedrich Schiller. Stuttgart, 1963. 
Strich, Fritz. Deutsche Klassik und Romantik. Bern, 1962.

wiese, Benno von. Schiller, Einführung in Leben und Werk. Stuttgart. 1966. 